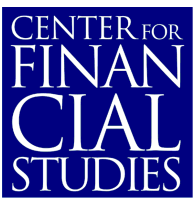

No. $2004 / 25$

The Basel II Accord: Internal Ratings and Bank Differentiation

\author{
Eberhard Fees and Ulrich Hege
}




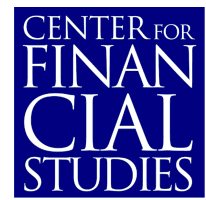

\section{Center for Financial Studies}

The Center for Financial Studies is a nonprofit research organization, supported by an association of more than 120 banks, insurance companies, industrial corporations and public institutions. Established in 1968 and closely affiliated with the University of Frankfurt, it provides a strong link between the financial community and academia.

The CFS Working Paper Series presents the result of scientific research on selected topics in the field of money, banking and finance. The authors were either participants in the Center's Research Fellow Program or members of one of the Center's Research Projects.

If you would like to know more about the Center for Financial Studies, please let us know of your interest.

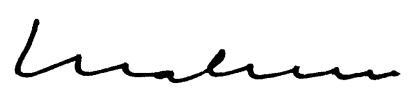

Prof. Dr. Jan Pieter Krahnen

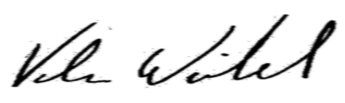

Prof. Volker Wieland, Ph.D. 
CFS Working Paper No. 2004/25

\title{
The Basel II Accord: Internal Ratings and Bank Differentiation*
}

\author{
Eberhard Feess ${ }^{1}$ and Ulrich Hege ${ }^{2}$
}

\section{December 2004}

\begin{abstract}
:
The Basel Committee plans to differentiate risk-adjusted capital requirements between banks regulated under the internal ratings based (IRB) approach and banks under the standard approach. We investigate the consequences for the lending capacity and the failure risk of banks in a model with endogenous interest rates. The optimal regulatory response depends on the banks' inclination to increase their portfolio risk. If IRB-banks are well-capitalized or gain little from taking risks, then they will increase their market share and hold safe portfolios. As risk-taking incentives become more important, the optimal portfolio size of banks adopting intern rating systems will be increasingly constrained, and ultimately they may lose market share relative to banks using the standard approach. The regulator has only limited options to avoid the excessive adoption of internal rating systems.
\end{abstract}

\section{JEL Classification: K13, H41}

Keywords: Basel II Accord, risk-based capital, internal ratings based approach, bank capital, bank competition, risk-taking.

\footnotetext{
*We are grateful to Jan-Pieter Krahnen for helpful comments and discussions. Oliver Humpert provided excellent research assistance. Financial support from Center for Financial Studies is gratefully acknowledged.

${ }^{1}$ Corresponding author. Address: Aachen University (RWTH), Dept. of Economics, Templergraben 64, D-52056 Aachen, Germany. E-mail feess@rwth-aachen.de

2 Address: HEC School of Management, Department of Finance and Economics, F-78351 Jouy-en-Josas Cedex, France. E-mail hege@hec.fr
} 


\section{Introduction}

Motivation. The new Basel II Accord scheduled for implementation after 2006 will have a substantial and lasting impact on the structure of the banking industry. The capital adequacy guidelines proposed by the Basel Committee ${ }^{1}$ are intended to tailor the minimum capital requirements more accurately to the true credit risk afforded by each individual bank loan or other asset. This objective is to be achieved by a two-pronged reform: first, a more precise differentiation among credit risks; second, by introducing a dual approach of distinguishing between the Standard Approach (SA) and the Internal Ratings Based Approach (IRB).

Under the SA regulation, certified credit rating agencies will assign risk coefficients to bank loans and other bank assets, and for commercial bank loans without an external rating, the risk weight will be assumed to be $100 \%$. By contrast, under the IRB regulation, banks will be authorized to undertake the risk classification of assets themselves according to their own credit scoring models. The Basel Committee plans to set a high regulatory standard for banks operating under the IRB approach, but wants to increase the attractiveness of investing into the IRB approval process. Therefore, the Committee has announced that it will offer a reduction of $2-3 \%$ in the required capital, compared with the capital needed for the same risk-weighted asset portfolio under SA.

A consequence of the Basel Accord is that by advocating IRB, the power to determine the minimum capital requirements for individual bank assets is effectively delegated to the banks themselves. The idea is to benefit from the banks' vastly improving expertise in rating the credit risk of their assets, and to avoid the duplication of credit evaluation efforts that the banks needs to undertake anyway. But delegating regulatory decisions to the regulated entity raises genuine concerns about possible agency conflicts. Banks can use their rating power to manipulate their risk assessments in order to reduce their overall required capital. Thus, the first objective of our paper is to address the newly emerging agency problems between regulator and banks using IRB. We consider three moral hazard problems and their possible interaction: banks' risk-taking, banks' misreporting of their portfolio risk, and banks' excessive adoption of unregulated advanced

\footnotetext{
${ }^{1}$ See Basel Committee (2004). The proposal povides for three distinct pillars of banking regulation, (i) standards for capital adequacy, (ii) banking supervision and (iii) market discipline. In this paper, we will exclusively focus on the most prominent of these pillars, the one on capital adequacy. While the pillars are probably regulatory substitutes to some extent (this has been pointed out e.g. by Acharya, 2003, Decamps, Rochet and Roger, 2004 or Morrison and White, 2004), our perspective is the optimal design of the capital adequacy pillar, once the optimal weight for each of the three pillars is determined.
} 
scoring systems. ${ }^{2}$

The dual approach of offering two different regulatory standards is likely to profoundly affect the capacity to make informed lending decisions, the level of competition and interest rates, the charter value and the failure risk of banks. An appropriate investigation of these questions requires a model that allows to analyze the general equilibrium consequences within the entire banking sector. The proposed Basel II Accord has so far only been studied with respect to a single bank or in a partial equilibrium framework, i.e. for a given market structure of the banking sector. The second objective of our paper is thus to analyze how an optimal implementation of the Basel II dual approach will affect the market shares of banks operating under IRB relative to banks operating under SA. We are not aware of a previous formal analysis linking these two issues, bank moral hazard and the evolving bank market structure under Basel II.

The Basel Committee's stated intention is that Basel II will lead banks to make improvements in their internal rating capabilities. These improvements are costly, and so a third objective of our paper is to link an analysis of the market structure under Basel II to the incentives to invest in internal rating systems.

Analysis and Results. We consider the simplest possible model for our purposes, an economy with two banks and two types of projects. Safe projects feature a higher expected return and lower risk than risky projects. Initially, neither banks nor rating agencies or the regulator can discriminate between safe and risky projects. One of the banks, however, has the option to invest in an improvement of its credit scoring system and will then be able to screen between safe and risky projects. With this investment, the bank qualifies to use the IRB approach.

Our analysis initially shows that the optimal regulatory response is to assign lower riskadjusted capital requirements to the IRB-bank compared with the SA-bank, thus confirming the stated intention of the Basel Committee. The reason is that there are economies of scale in absorbing risks. As long as the IRB-bank will select a predominantly safe loan portfolio, the regulator will assign low capital requirements to the IRB-bank that, as the relatively safer bank, should grow in order to provide protection against bank failure risks for a larger part of the econ-

\footnotetext{
${ }^{2}$ Within the IRB-approach, the Basel Committee distinguishes between a foundation approach and an advanced approach. Under the foundation approach, the IRB-banks' own assessment is restricted to the probability of default (PD), whereas advanced IRB-banks use their own systems also to estimate the loss given default (LGD) and the exposure at default (EAD) (see Basel Committee (2004), Part 2, III). Though interesting, this distinction is neglected in our model as expected social bankruptcy costs depend only on which projects are funded.
} 
omy. Thus, there is a beneficial differentiation effect concerning both the size and the risk of the two banks' loan portfolios, as heterogeneity in banks' leverage ratios and risk levels increases overall welfare. As a result, the regulator will discriminate in favor of the bank with the better portfolio quality, i.e. the IRB-bank if it prefers safe projects. The IRB-bank's market share increases, and the market share of the SA-bank decreases. This result provides a rationale for keeping large banks safe - or in fact, for allowing safe banks to become large.

A second beneficial consequence of the differentiation among banks is a decline in the level of bank competition due to an interest rate effect. As long as the IRB-bank uses its superior screening capabilities to select more safe projects, the interest rates determined by the possible market entry of SA-banks, will increase and the IRB-bank will garner additional rents. The associated increase in banks' profit means that the failure risk is reduced. The banking literature has discussed the beneficial impact of reduced competition on bank stability. Our analysis contributes to this strand of literature with the insight that only IRB-banks will benefit from higher profits and more stability, while there is no positive effect for SA-banks.

The selection of a safer loan portfolio by the IRB-bank negatively affects the loan quality of projects available for SA-banks, which is not only the reason why interest rates increase, but also means an increased failure risk for SA-banks. Our paper sheds light on this important effect of the Basel II regulation: by improving the screening capabilities of banks using internal scoring systems and giving them incentives to choose low-risk projects, the new system inflicts damage on the asset quality of the remaining banks. Since the SA-banks will inevitably be among the smallest and weakest banks in a financial system, this general equilibrium effect will further add to their fragility. Nevertheless, we find that the welfare under the dual approach is higher than if all banks are SA-regulated, due to the competition effect and the size and risk differentiation effect.

Up to this point, our analysis has not yet taken into account that IRB-banks might be inclined to increase the riskiness of their assets, by exploiting their informational advantage and misreporting their true risk levels so as to benefit from lower capital requirements. To explore this important agency problem, our model makes the extreme assumption that IRB-banks have full discretion to misrepresent the actual riskiness of their assets without having to fear any penalties or consequences. IRB-bank might then tend to aggressively adopt and misreport risky projects due to a simple risk-shifting effect or limited liability effect well-known from the bank regulation literature. The initial equity endowment of banks and the difference in returns between safe and risky projects determines the relative attractiveness of risk-taking. 
We find that, as risk-taking incentives increase, the regulator will raise the capital requirements for IRB-banks to ensure that their portfolios remain safe. Gradually, the size differentiation effect of the dual approach under the Basel II Accord will be lost, and Basel I may be socially superior if equity endowments are relatively high, as a uniform regulation provides then for a better risk allocation across banks. When risk-taking incentives are very high, then the regulator will optimally limit the IRB-bank's lending so much that it will face higher capital adequacy ratios than the SA-bank, and experience a drop in its market share after investing in an internal rating system. If risk-taking incentives are even higher, the optimal policy may again be reversed: the regulator may then find it optimal to let the IRB-banks absorb a large portion of risky assets in order to balance the overall risk allocation.

In the final step of our analysis, we consider the investment outlays necessary to meet the IRB-standards. We show that the incentives of banks to invest into their IRS capabilities will usually not coincide with the optimum for the regulator. The reason for these suboptimal investment incentives are twofold: first, the banks' equityholders will not consider the social cost of their failure. Second, their gains from bank differentiation may exceed the social benefits since shareholders take only the positive effects into account, while ignoring the declining size and deteriorating loan portfolio of the other banks in the industry. Compared with the socially optimal investment level, banks are likely to overinvest into their internal rating systems if the social costs of bank failure are low, and to underinvest if social costs are high. We assume (realistically) that banks have discretion to improve their internal rating capabilities while continuing to be regulated under the standard approach.

We show that the regulator's best choice of instrument, in order to correct these investment inefficiencies, are lump-sum transfers, and not penalties or discounts on the capital adequacy ratios. The reason is that the regulator pursues the double objective of providing optimal investment incentives and ensuring an optimal portfolio allocation across banks, and she needs two separate policy instruments (transfers and capital adequacy ratios) to avoid conflicts between both objectives. We find that the regulator will normally be able to correct underinvestment incentives, but is relatively powerless when faced with banks that invest too aggressively into their IRS capabilities. This problem is aggravated by the banks' discretion to invest into IRS capabilities without formally operating under the IRB approach. The best the regulator can do is then to accommodate the banks' excessive adoption of IRS capabilities, and in some cases even to offer subsidies to banks to entice cooperation with the IRB regulation.

Thus, we conclude that a success of Basel II, in terms of banks massively and early embracing 
the IRB approach, should not be mistaken as a sign that this is an efficient arrangement. It may simply be indicative of a situation where banks improve their rating capabilities to take advantage of risk-shifting opportunities, and where accommodation is the best option for a relatively powerless regulator.

Relation to the Literature. Our paper is related to the vast literature on bank capital and its optimal regulation and more specifically, to the numerous papers on risk-taking by banks and the regulation of bank capital (see Bhattacharya, Boot and Thakor, 1998, Santos, 2001, and Allen, 2004, for surveys). Acharya (2001) endogenizes the choice of systemic risk in a bank loan portfolio and discusses the regulatory consequences. Tighter capital requirements have been argued to increase risk-taking incentives (Thakor, 1996), Besanko and Kanatas, 1996), to reduce them (Repullo, 2000), or to have mixed effects (Calem and Rob, 1999). In respect to the competition effect, Matutes and Vives (1996) show that reduced banking competition mitigates risk-taking incentives. Hellmann, Murdock and Stiglitz (2000) also emphasize negative effects of strong competition and discuss the impact of monitoring. Morrison and White (2004) point out that the impact of capital adequacy ratios on risk taking may depend on the regulator's monitoring competence. Boot and Greenbaum (1993) argue that excessive risk taking can be mitigated by reputation effects. Since the benefit of reputation decreases in the degree of competition, imperfect competition may be welfare-improving.

There is also a literature analyzing the banks' incentives to understate their portfolio risk when using internal ratings. Similar to Morrison and White (2004), Marshall and Venkatamaran (1999) and Dangl and Lehar (2002) argue that the benefit from internal rating depends on the regulator's monitoring quality and punishment potential. Gersbach and Wehrspohn (2001) argue that banks will underinvest in their scoring models because they will identify bad loans more often, which leads to higher capital adequacy ratios with internal rating, but they do not consider that credit risks may be opportunistically misstated.

The paper closest in spirit is Repullo and Suarez (2003) who model a competitive banking sector where borrowers choose between IRB-banks and SA-banks. In their paper, IRB-banks will always specialize in riskier, and the average interest rate after Basel II decreases. In our model, both cherry picking and risk-shifting is possible, and the interest rate increases if IRB-banks prefer cherry picking, so that our conclusions are strikingly different from their. The reason is that, contrary to our analysis, they do not consider bank moral hazard and do not choose capital requirements to maximize social welfare, since their focus is on simulating the general equilibrium 
effects of Basel II.

Empirical literature on potential impacts of the Basel II Accord has focused on the likely procyclical effects. Altman and Saunders (2001) demonstrate that external ratings and hence the SA component of Basel II would be likely to be procyclical, employing simulations for the US recession 1989-91. Montfort and Mulder (2000) and Peura and Lokivuolle (2004) find the same procyclical effect for internal rating systems. Calibrating data from American banks, Furfine (2001) predicts that Basel II would lead to fewer risky loans, but also to more lending overall and a lower portfolio weight of riskfree bonds, making the overall effect on the portfolio risk ambiguous. Another strand of the literature has investigated the consistency of internal and external ratings to predict default risks, for example Carey (2001), Gropp and Richards (2001) and Claessens and Embrechts (2003).

The paper is organized as follows. Section 2 introduces the model. In Section 3, we derive the banks' profits and social welfare in case of two SA-banks. Section 4 analyzes the case where Bank $A$ has invested and prefers safe projects to risky (and low-return) projects. Section 5 introduces Bank $A$ 's portfolio choice, which turns out to be a problem of risk-shifting, and presents an analysis of the interaction between regulator's and bank's decision-making. Section 6 discusses robustness issues and concludes.

\section{The Model}

Banks and Projects. Our model consists of two banks, Bank $A$ and Bank $B$. Initially, both banks have rating systems of low quality. However, Bank $A$ can invest $C \geq 0$ into improving its rating system. If $C$ is invested, Bank $A$ acquires an internal rating system (IRS) that is sufficient to qualify for the use of internal ratings (IRB) under the Basel II Accord. ${ }^{3}$ If Bank $A$ invests $C$, it has the option to submit its IRS to the regulator, who can verify the quality of the IRS and will grant approval to Bank $A$ to operate as an IRB-bank. Note that, for simplicity, only Bank $A$ has an option to invest and to become an IRB-bank. The investment in an IRS is really a technical decision to upgrade the bank's information system, and the bank could undertake this investment independently of the regulatory environment. We therefore assume that Bank $A$ can also choose to invest in an IRS, at a cost of $C$, without requesting to be regulated as an IRB-bank. A bank (Bank $A$ or Bank $B$ ) that uses the standard approach is called a SA-bank. We call the regulation

\footnotetext{
${ }^{3}$ The argument would not change if we assumed instead that the investment is only successful with some probability $q(C)$.
} 
of the banking sector "Basel I" if both banks are uniformly regulated as SA-banks, and refer to the regulation as "Basel II" if Bank $A$ becomes an IRB-bank. Banks are risk neutral and have identical equity endowments of $E$.

The economy consists of a continuum of projects with a total measure of one. Any portfolio with positive measure consists of an infinity of projects. All projects require an identical investment outlay that we normalize to a unit of investment, i.e. funds worth $n$ are needed to finance a portfolio of measure $n \leq 1$. The return (rate of return plus one) of each project is $X$ if it succeeds, and zero if it fails. $X$ is the project's total return, which is different from the (endogenous) return to the bank, $R$, which is principal and interest. Distinguishing between total (social) return and the bank's (private) return is an essential ingredient of our analysis, since we want to conduct a comprehensive analysis of the investment incentives in internal rating systems.

We assume that $\frac{1}{2}$ of the projects are "safe", and $\frac{1}{2}$ of them are "risky". Safe projects yield $X$ with probability $k \geq \frac{1}{2}$, and nothing with probability $1-k$. The realizations of safe projects are uncorrelated, meaning that the return of any measurable portfolio of safe projects will be exactly $k X$. Risky projects do not only yield a lower average return, but they are also strongly correlated. To capture this in a simple way, we assume that a portfolio of measure $n$ of risky projects yields $\operatorname{tn} X$, where $t \in[0,1]$ is a uniformly distributed random variable. Thus, the random variable $t$ indicates the realization of the systematic risk in the loan portfolio. Since the expectation of $t$ is 0.5 , the average return of a risky project is $\frac{1}{2} X \leq k X$. We come back to the assumption that $k \geq \frac{1}{2}$ in Section 6 .

With respect to the information structure, we assume that the type of project is unobservable to SA-banks, to external rating agencies, and to the regulator. By contrast, if Bank $A$ becomes an IRB-bank, it can perfectly discriminate between safe and risky projects. As to external ratings, this expresses the idea that rating agencies provide less accurate signals about the credit risk than sophisticated internal rating systems. ${ }^{4}$

Bank Failure. We assume $X>2$ so that financing even risky projects would be socially worthwhile if there were no bankruptcy risk. If there is a bankruptcy event for one of the two banks, this is assumed to involve a real cost for society, the loss of the social charter value $Z$ of the bank. Primarily, this social cost $Z$ of bank failure consists in the disruption of the financing and payment flows for the bank's customers (borrowers and lenders), a disruption that will show

\footnotetext{
${ }^{4}$ This idea seems to be widely shared by industry practitioners. It is also implied by the literature emphasizing the uniqueness of bank loans, following James (1987).
} 
some persistence if the customers have privileged relationships with the failed bank. This type of social costs of a bank failure is roughly proportional to the size of bank's assets, and thus we assume that the social loss of a bank failure is $n z$. We denote the expected bankruptcy loss by $Z=\operatorname{Prob}($ bankruptcy). $n z$. Notice that even if there were additional contagion effects (we ignore these in our model), for example if customers of a failed bank were to trigger the insolvency of other projects in the economy, then in an economy of homogeneous projects, with a homogeneous degree of interfirm credit and payment linkages, the total effect of all direct and indirect effects would again be proportional to the loan portfolio size of the initially failed bank.

Ratings, Capital Adequacy Ratios and Regulation. The regulator's instruments in our model are capital adequacy ratios $b$, which depend on the type of bank regulation (SA-bank or IRB-bank), and the riskiness of the loan, i.e. the declared quality of the project it finances. For projects financed by a SA-bank, external ratings will be consulted in accordance with the procedures under the proposed Basel II Accord. Since regulator and bank have the same information on loan selection, the effect of external rating is that for an SA-bank, all projects will be considered as being unidentified, and hence assumed to be safe or risky with the exact probabilities which the bank expects to draw them.

By contrast, we assume that an IRB-bank can opportunistically misrepresent the types of the projects it finances, and the regulator has no monitoring or disciplining capabilities to prevent it from doing so. As we will see, this has an influence on the optimal choice of capital adequacy ratios. While this is certainly an extreme assumption, we employ it to capture one of the essential agency conflicts of internal rating systems: banks will always have better knowledge and control of their IRS than regulators, and they are likely to use this informational asymmetry to their advantage. Any imperfect monitoring technology that the regulator possesses to evaluate the outcome of the internal ratings process would weaken, but not abolish this agency conflict. ${ }^{5}$

The regulator can use other incentives devices, besides capital adequacy ratios $b$, to induce Bank $A$ to make an optimal investment decision. We consider lump-sum transfers that are paid to Bank $A$ if it obtains regulatory approval to operate as IRB-bank. This transfer could be positive (a subsidy to the bank) or negative (a tax) and is denoted by $s$. The regulator has no power to impose transfers on SA-banks (assuming so would not be realistic), or to employ a

\footnotetext{
${ }^{5}$ Even if the regulator uses advanced statistical models to track the performance of the bank's internal rating system, manipulation will easily be possible at least in the short term: namely, manipulation-induced losses are initially indistinguishable from bad luck in the portfolio return realization.
} 
command-control approach to determine the investment decision.

Equilibrium on the Loan Market. Let $R$ be the interest factor (interest rate plus 1). We assume that the interest rates in this economy are determined competitively, in the following sense: the competitive interest rate is set such that any new potential market entrant that contemplates entering the market as an SA-bank will make zero profits on its first project. This idea is akin to the concept of a contestable market for loans. It does not exclude that at the same time the two incumbent banks can make positive profits, even when they are SA-regulated, namely if their loan portfolios are large enough that they benefit from the option value provided by a positive bankruptcy probability (this is indeed what we will observe). The interest rate is then endogenous: it depends in fact on the quality of the project that any entering bank expects to pick up. To tie this down in a precise manner, we assume that Bank $A$ first picks its portfolio, i.e. it screens all projects and retains only those projects that it wants to fund. This timing will give a first mover advantage to Bank $A$ only if it has adopted an IRS and therefore is able to observe the project types accurately. The quality of projects funded by Bank $B$ (or any potential market entrant) corresponds then to the average quality of projects in the remaining pool after Bank $A$ has made its choice. Therefore, with differentiated banks, the expected portfolio of any market entrant depends on Bank $A$ 's project choice, and therefore the interest rate depends on the equilibrium belief on Bank $A$ 's portfolio choice. ${ }^{6}$ The endogeneity of the interest rate is an important aspect of our analysis.

Timing. The timing of the game is as follows:

Stage 1. The regulator makes a credible announcement on the conditions that govern the subsequent investment decision. These conditions can be summarized by a subsidy/tax $s$ for Bank $A$ if it gets approval as an IRB-bank.

Stage 2. Bank $A$ chooses one of three options regarding investment $C$. First, Bank $A$ can decide not to invest, in which case both banks are identical. Second, Bank $A$ may invest in an IRS but hide its IRS capabilities from the regulator. Third, Bank $A$ may invest and submit its IRS to the regulator, who will then always recognize the bank as an IRB-bank. If Bank $A$ does not invest or does not submit, then the regulation of the banking sector will be uniform (as under

\footnotetext{
${ }^{6}$ For some parameters, multiple equilibrium beliefs may arise. In this case, we select the beliefs of a market entrant (and hence $R$ ) that are consistent with the efficient equilibrium, which is the equilibrium with the smallest amount of risk-shifting.
} 
the Basel I Accord). If Bank $A$ invests and obtains IRB-status, then the regulation of the banking sector can be differentiated, as under the Basel II Accord.

Stage 3. The regulator announces the menu of capital adequacy ratios $b$.

Stage 4. Bank $A$ makes its portfolio choice. If it has invested in an IRS, it has the opportunity to screen all projects and to pick those that it wishes to fund. Then, Bank $B$ makes its project choice, and the interest factor $R$ is determined such that a market entrant (SA-bank) expects to make zero profits. Since Bank $A$ 's true portfolio choice is unobservable, $R$ is determined by the equilibrium belief on $A$ 's choice.

Stage 5. Nature decides upon the success of projects. This also determines if a bank is insolvent or not.

Figure 1 contains a game tree that summarizes all 5 stages of the game. We will solve for the subgame perfect equilibrium (SPE) of the game using backwards induction. Since stage 5 is a chance move by Nature, we have to begin to work backwards in stage 4, where banks decide on their portfolios.

\section{Uniform Bank Regulation: Basel I Accord}

We start with the case where Bank $A$ has not invested in an IRS, so both banks possess the same rating quality and will be regulated as SA-banks. So this case is in fact equivalent to the regulatory situation under the Basel I Accord. For this case, we use the superscript $u$ (for "uniform"), and we will directly derive the banks' optimal decisions given the capital adequacy ratio $b$ (stage 4 ) and the regulator's optimal $b$ (stage 3 ). The same will then be done under the assumption that Bank $A$ has invested in section 4 . Under Basel I, both banks face the same capital adequacy ratio $b_{u}{ }^{7}$ and the number of projects funded by each bank is $n_{u} \leq \frac{E}{b_{u}}$. Applying backwards induction, we first analyze profits and bankruptcy risks as a function of $n_{u}$ (stage 4), then turning to the regulator's choice of the optimal $b_{u}$ given that we have a uniform banking sector (stage 3 ).

We assume that equity $E$ is insufficient to allow for all projects to be financed without that banks would ever incur a risk of insolvency. This uninteresting case is excluded if $E \leq \frac{1}{2(1+2 k)}$, which we will assume throughout the paper. Since banks cannot discriminate between safe and risky projects, each loan portfolio consists of $\frac{n_{u}}{2}$ safe and $\frac{n_{u}}{2}$ risky projects. For given $n_{u}$ and $E$, the bank will avoid insolvency if the realization of the systematic shock $t$ is large enough such

\footnotetext{
${ }^{7}$ We assume that the regulator cannot discriminate between two identical banks, for example because of legality concerns. Such a discrimination would be attractive in our model as we will see later on.
} 
that the bank's assets are at least equal to its liabilities, or if

$$
\frac{n_{u}}{2} k R+\frac{n_{u}}{2} t R+E-n_{u} \geq 0
$$

Let $\tilde{t}_{u} \geq 0$ denote the minimum value of $t \geq 0$ satisfying (3.1). Because $t$ is uniformly distributed over the unit interval, $\tilde{t}_{u}$ conveniently embodies also the bankruptcy probability. The expected profit per bank can then be expressed as:

$$
\Pi_{u}=\left(1-\tilde{t}_{u}\right)\left(\frac{n_{u}}{2} k R+\frac{n_{u}}{2} E\left[t \mid t>\tilde{t}_{u}\right] R+E-n_{u}\right),
$$

where $R$ is the (endogenously determined) interest factor. If the bank avoids insolvency, which it does with probability $1-\tilde{t}_{u}$, then the return from safe projects is $k R$ with certainty, and the expected return from risky projects is $E\left[t \mid t>\tilde{t}_{u}\right] R=\frac{1+\tilde{t}_{u}}{2} R$. The latter depends on the conditional expectation of $t \geq \tilde{t}_{u}$. Furthermore, the bank owns $E$ and invests $n_{u}$, explaining the remaining terms in Eq. (3.2).

Recall that we determine $R$ by assuming that a marginal project expected by a SA-bank breaks even. Since the marginal project is an unidentified one in case of uniform banks, it is safe or risky with probability 0.5 each. Hence, we have $0.5 \cdot k R+0.5 \cdot 0.5 \cdot R=1$, or $R=\frac{4}{(1+2 k)}$.

Substituting for $R$ and rearranging Eq. (3.2) yields

$$
\Pi_{u}=\left(1-\tilde{t}_{u}\right)\left(\frac{2 k}{(1+2 k)} n_{u}+\frac{1+\tilde{t}_{u}}{2} \frac{n_{u}}{2(1+2 k)}+E-n_{u}\right) .
$$

The insolvency threshold $\tilde{t}_{u}$ is reached when the return to the bank, including its capital reserves $E$, is not enough to cover the deposits ${ }^{8}$ of investors worth $n_{u}$, i.e. if

$$
\tilde{t}_{u}=\max \left(\frac{n_{u}-E(1+2 k)}{2 n_{u}}, 0\right) .
$$

Substituting into the bank's profit function (3.3) and rearranging yields

$$
\Pi_{u}=\frac{\left[2 n_{u}+2 E(1+2 k)\right]^{2}}{16 n_{u}(1+2 k)} .
$$

Note that $\Pi_{u}$ is strictly increasing in $n_{u}$, because the bank does not have to pay for the losses if it becomes bankrupt due to a low realization of $t$. Hence, SA-banks fund as many projects as possible, meaning that $n_{u}=\frac{E}{b_{u}}$. The total social welfare is:

\footnotetext{
${ }^{8}$ The depositors are paid the risk-free interest rate of 0 . Thus, we implicitly assume that there is a deposit insurance scheme in place that effectively covers all credit risk for the depositors. We also assume that the pricing of the deposit insurance does not depend on its current loan portfolio decision. Therefore, the bank's payment for deposit insurance premia can be ignored.
} 


$$
\begin{aligned}
W_{u} & =\frac{1}{4}(1+2 k) 2 n_{u} X+2 E-2 n_{u}-2\left[\frac{n_{u}-E(1+2 k)}{2 n_{u}}\right] n_{u} z \\
& =\frac{1}{2}(1+2 k) n_{u} X+2 E-2 n_{u}-\left[n_{u}-E(1+2 k)\right] z .
\end{aligned}
$$

Here, $\frac{1}{4}(1+2 k) X$ is the expected return of an unidentified project which enters the social welfare regardless of the division of the return between project owners ${ }^{9}$ and banks, since all players are assumed risk-neutral. Total equity of the two banks is $2 E$, and the projects require investment outlays of $2 n_{u}$. Finally, each banks goes bankrupt with probability $\frac{n_{u}-E(1+2 k)}{2 n_{u}}$, and then causes costs of $z n_{u}$. Eq. (3.6) leads to

Proposition 1. If the project return $X$ satisfies $X \geq \frac{2}{1+2 k}(z+2)$, then the regulator will choose $b_{u}=2 E$ and all projects will receive financing $\left(n_{u}=\frac{1}{2}\right)$. Bank failure will occur with positive probability. Otherwise, the regulator will choose $b_{u}=\frac{1}{1+2 k}$, each bank will finance less than half of the available projects, $n_{u}=E(1+2 k)<\frac{1}{2}$, and banks will never fail.

\section{Proof. See Appendix.}

The interesting point in Proposition 1 is that the regulator will either allow to fund all projects or will avoid any bankruptcy risk at all. The intuition for this corner solution result is that marginal expected bankruptcy costs (with respect to $n_{u}$ ) are equal to $\frac{z}{2}$, and thus independent of $n_{u}$. Since the expected marginal social benefit from a risky project is also constant and given by $\frac{X}{2}-1>0$, there is no interior solution. The condition stated in the Proposition that distinguishes between both cases, $X \geq \frac{2}{1+2 k}(2+z)$, simply says that the expected social benefit of an additional project, exceeds its total costs including the additional bankruptcy risk.

We encounter here already a property that will play a prominent role in our further analysis: the fact that the marginal bankruptcy probability is decreasing in the number of projects implies that social welfare could be increased by an asymmetric split between the two banks. As long as banks are identical, however, such a discrimination is excluded by the legality principle.

Clearly, the critical threshold for $X$ where the regulator does no longer want all projects to be funded, depends also on $z$ and $k$ since the regulator's incentive to allow for all projects is

\footnotetext{
${ }^{9}$ It does not make any difference whether project owner's can fully extract $X-R$ or whether part of this difference goes to consumers.
} 
increasing in the expected return and decreasing in bankruptcy costs. In general, the parameter regions where the regulator allows for all projects are different in the cases with uniform and differentiated banking sectors. Discussing all possible situations leads to tedious and economically non-essential case distinctions, that would be further complicated by the fact that the parameters $z$ and $k$ are also important to determine various cases of risk-shifting and investment incentives and the regulatory response to them. To avoid these cases and to focus on the paper's central question whether internal rating is a good thing even in light of Bank $A$ 's option to systematically adopt risky projects, we introduce the following Assumption:

Assumption 1: The project return $X$ is sufficiently large so that the regulator always prefers to have all projects funded.

A sufficient condition for Assumption 1 to hold in all situations is that $X \geq 2+z$, that is if the expected return of a risky project exceeds the investment and bankruptcy loss even if the bank is sure to fail. Even though the total lending volume is now independent of the regulator's decision and Bank $A$ 's adoption of an IRS, the analysis is rich since the portfolio composition, the optimal regulatory policy and the two banks' failure probabilities still depend on these decisions and how they interact. With Assumption 1, the only variables having an impact on total welfare are (i) the cost of bank failure, which is the overall expected cost of bankruptcy for both banks combined, and (ii) the investment costs if Bank $A$ adopts an IRS. For future reference, we note that then in the case of a uniformly regulated banking sector, the expected bankruptcy loss $Z_{u}$ can be written as, using Eq. (4.10) and $n_{u}=\frac{1}{2}$ :

$$
Z_{u}=\left[\frac{1}{2}-E(1+2 k)\right] z
$$

\section{Basel II Regulation}

In this Section, we assume that Bank $A$ has invested in an IRS and has been certified as an IRB-bank. The analysis is more complex than before, because Bank $A$ can now decide whether it prefers to fund safe or risky projects, and because the regulator can differentiate between the two banks. The decisions of the regulator and Bank $A$ do in fact interact: Bank $A$ 's portfolio choice depends, among others, on the previous regulatory decision on the capital adequacy ratios $b$. And there is an important feedback effect since the regulator's optimal capital adequacy regulation depends on Bank A's portfolio allocation. 
Therefore, we develop our analysis step-by-step: In Section 4.1, we ignore the risk-taking problem by simply assuming that Bank $A$ always chooses safe projects. We then solve the game tree going backwards: in Section 4.2, we consider Bank $A$ 's portfolio decision (Stage 5 in the game tree), but do not yet endogenize the regulator's optimal actions. We then account for the regulator's sequential decisions: in Section 4.3, we analyze the optimal choice of capital adequacy ratios (Stage 4 of the game). Finally, in Section 4.4 we consider the case where Bank $A$ has decided to invest in an IRS, but did not apply for a license (Stage 3), before we turn in Section 5 to the regulator's initial decision (Stage 1). ${ }^{10}$

\subsection{Preference for Safe Projects}

As explained above, we first abstract from any risk-taking incentives for Bank $A$. If Bank $A$ invests and receives the status of an IRB-bank, then the regulator will in principle apply different capital adequacy ratios for safe and for risky projects, respectively. However, recall that an IRB-bank can entirely misrepresent the appraisals supplied by its internal ratings system. In equilibrium, it will use this discretion to its advantage. In our model, this means that it will be able to obtain the lowest available $b$ for every project it finances. Thus, the effective capital requirement ratio for an IRB-bank will be a uniform rate, $b_{I}$ : if the regulator applies different ratio for safe and risky projects, say $b_{g}$ for projects identified as safe and $b_{b}$ for projects identified as risky, then Bank $A$ will declare all of its loans as belonging to the category that is taxed less in terms of capital requirements, and $b_{I}=\min \left\{b_{g}, b_{b}\right\}$ will be the effective rate. As a result, Bank $A$ can finance exactly $n^{A}=\frac{E}{b_{I}}$ projects. Assuming that $n^{A} \geq \frac{1}{2}$, the equilibrium profits of Bank $A$ are: ${ }^{11}$

$$
\Pi_{c}^{A}=\left(1-\tilde{t}^{A}\right)\left[\frac{1}{2} k R+E\left[t \mid t>\tilde{t}^{A}\right] R\left(n^{A}-\frac{1}{2}\right)+E-n^{A}\right]
$$

where $\tilde{t}^{A}$ is the bankruptcy probability and $n^{A}$ is the number of projects in the loan portfolio of Bank $A$. The equilibrium interest factor is $R=2$, since Bank $B$ will only fund risky projects. Substituting for $R$ yields:

$$
\Pi_{c}^{A}=\left(1-\tilde{t}^{A}\right)\left[k+E\left[t \mid t>\tilde{t}^{A}\right] 2\left(n^{A}-\frac{1}{2}\right)+E-n^{A}\right] .
$$

\footnotetext{
${ }^{10}$ Although it will turn out that this can never be a SPE, Bank $A$ 's possibility to invest without applying for a licence may influence the regulator's optimal policy, and therefore needs to be taken into account.

${ }^{11}$ The bank profit $\Pi_{c}^{A}$ refers to the bank's operating profit neglecting investment $\operatorname{costs} C$ and subsidies $s$. Occasionally, we wiil refer to the bank's overall profits as $\hat{\Pi}_{c}^{A}$, i.e. $\hat{\Pi}_{c}^{A}=\Pi_{c}^{A}+s-C$.
} 
The bankruptcy threshold of Bank $A$ is again the smallest value of $t$ where the square bracket [.] in Eq. (4.2) is equal to zero, and this threshold value will be identical to the bankruptcy probability $\tilde{t}^{A}$ :

$$
\tilde{t}^{A}=\max \left\{\frac{n^{A}-E-k}{2 n^{A}-1}, 0\right\} .
$$

Bank $B$ is allowed to fund $1-n^{A}$ projects and, with an interest factor of $R=2$, earns profits of:

$$
\Pi_{c}^{B}=\left(1-\tilde{t}^{B}\right)\left[\left(1-n^{A}\right) E\left[t \mid t>\tilde{t}^{B}\right] 2+E-\left(1-n^{A}\right)\right] .
$$

Bank $B$ 's bankruptcy threshold $\tilde{t}^{B}$ can be determined as, in analogy to Eq. (4.3):

$$
\tilde{t}^{B}=\max \left\{\frac{1-n^{A}-E}{2\left(1-n^{A}\right)}, 0\right\} .
$$

We denote the combined expected bankruptcy costs of both banks by $Z_{c}$ in the case where Bank $A$ invests, is regulated as an IRB-bank and prefers safe projects. This cost can be written as

$$
Z_{c}\left(n^{A}\right)=n^{A} \tilde{t}^{A} z+\left(1-n^{A}\right) \tilde{t}^{B} z,
$$

where $\tilde{t}^{A}$ and $\tilde{t}^{B}$ are as in Eq. (4.3) and (4.5). Minimizing $Z_{c}$ by choosing the optimal $n^{A}$ and comparing it to the cost of bank failure $Z_{u}$ in the Basel I scenario given in expression (3.7), we get the following result:

Proposition 2. Suppose there is no risk-shifting. Then, the regulator chooses $b$ such that $n^{A}=k+E$, and Bank $A$ faces no bankruptcy risk. Total expected bankruptcy costs are then $Z_{c}(k+E)=\frac{1-2 E-k}{2} z<Z_{u}=\left[\frac{1}{2}-E(1+2 k)\right] z$.

Proof: See Appendix.

Proposition 2 says that, if there is no risk-shifting under Basel II, it is optimal for the regulator to avoid any risk of bank failure for the IRS-bank. The reason is that the regulator wants to shelter as many projects as possible from bankruptcy risk. Of course, keeping Bank $A$ safe means that the bankruptcy risk of Bank $B$ increases, but it will do so at a decreasing rate, since the bankruptcy probability evolves as a concave function of portfolio size. Moreover, the failure risk in Bank $B$ will affect the smaller loan portfolio. 
In effect, two concurring effects are on display here: first, there is an economies of scale effect in the allocation of bankruptcy risk, making an unequal allocation of overall failure risk more attractive from the regulator's point of view than an equal one. When comparing the Basel II and Basel I allocation, the combined bankruptcy loss of the banking sector is strictly lower under the allocation of Proposition 2 than under Basel I. A similar effect was in fact at work in our result in Proposition 1 where we found that the regulator will either permit financing of all projects, or keep all banks safe. Second, there is a shelter effect saying that the riskier bank should hold a relatively small and the less risky bank a relatively large portfolio, to allocate the social cost of any default event efficiently.

In a sense, the result of Proposition 2 provides a microeconomic rationale for a "too big to fail" policy in banking regulation. We will later confirm and refine this intuition in more detail.

\subsection{Risk-Shifting Incentives}

In the former section, we have simply assumed that Bank $A$ chooses safe projects first. Now, the bank's project choice after having adopted an IRS is endogenized. When choosing its loan portfolio, Bank $A$ faces a trade-off between a quality effect expressed by $k>0.5$, and a riskshifting effect, which captures the fact that risky projects offer an attractive option to shift risks from the bank's shareholders to its depositors. If the bank is insolvent, shareholders are protected from the downside loss by limited liability, but they fully enjoy the upside of a project's payoff.

Define $\alpha$ as the percentage of risky projects Bank $A$ adopts, and $1-\alpha$ as the fraction of safe projects. Analogously to the profit functions explained in the case of two SA-banks, the IRB-bank's profit function is then

$$
\Pi^{A}=\left(1-\tilde{t}^{A}\right)\left((1-\alpha) k R n^{A}+\alpha E\left[t \mid t>\tilde{t}^{A}\right] R n^{A}+E-n^{A}\right) .
$$

Recall that the interest rate $R$ depends on the remaining project pool along the equilibrium path. Note that $R$ is bounded in the interval $R \in\left(\frac{1}{k}, 2\right)$, where the lower (upper) bound corresponds to the case where only safe (risky) projects are left to the SA-bank.

The following Lemma expresses an important insight with respect to Bank $A$ 's project choice:

Lemma 1. If Bank $A$ adopts an IRS, it will strictly prefer either safe or risky projects. That is, it will choose the maximum feasible number $\min \left(\frac{1}{2}, n^{A}\right)$ of its preferred project type and the residual number $\max \left(n^{A}-\frac{1}{2}, 0\right)$ of the other. 
Proof. See Appendix.

The Lemma says that Bank $A$ first adopts only either safe or risky projects and then fills the remainder of its lending capacity with the other project type. We will refer to the case where the bank prefers risky projects as risk-shifting, and to the case where the bank prefers safe projects as cherry-picking. To understand the reason behind this result, recall that the bank's profit $\Pi^{A}$ is a call option on the true value of the loan portfolio, and the expected value of this call option exhibits the usual convex shape as a function of the risk choice $\alpha$. This is the reason why either safe or risky projects are strictly preferred throughout. In fact, given the linearity of the portfolio choice problem, it is not surprising that the risk choice must be a boundary solution. The outcome may at first appear somewhat counterintuitive: since the bank benefits from risk taking, one might perhaps think that the bank would at least adopt so many risky projects that there is some bankruptcy risk. The quality effect $k>0.5$, however, explains why the expected profit is strictly decreasing for small values of $\alpha$ when the bankruptcy probability is zero. Note that the Lemma implies directly that the bank always has an incentive to adopt an IRS if $C$ is negligible, because the Lemma says that risk-shifting or cherry-picking always yields a strictly larger profit than any mixed portfolio.

The next question is which of the two policies, cherry-picking or risk-shifting, Bank $A$ will prefer. As mentioned above, the analysis is complicated by the following endogeneity: on the one hand, the bank's decision does not only depend on $k$, but also on the number of projects $n^{A}$ it can finance via $b_{I}$. But on the other hand, the regulator's choice of $n^{A}$ may well depend on the bank's loan portfolio choice, since the regulator may wish to avoid risk-shifting. Using backwards induction, we can derive important results for Bank $A$ 's portfolio selection in the third stage of the game. If Bank $A$ has invested in an IRS, we get:

Lemma 2. Suppose Bank $A$ adopts an IRS. Then there exists a unique threshold $\bar{n}^{A}$ such that Bank $A$ will choose cherry-picking if $n^{A} \leq \bar{n}^{A}$ and risk-shifting if $n^{A}>\bar{n}^{A}$. The threshold $\bar{n}^{A}$ is strictly increasing in $k$ and $E$ over the interval $\bar{n}^{A} \in(0, k+E)$.

Proof. See Appendix.

We had seen earlier that the risk choice will always have a boundary solution. Lemma 2 says that the bank's risk choice will have a single switching point $\bar{n}^{A}$, which has quite intuitive comparative statics properties. An increase in $k$ means that safe projects are more attractive, 
and an increase in $E$ means that the bank has more to lose in case of bankruptcy. Thus, the smaller the difference in expected returns between safe and risky projects, and the more Bank $A$ is levered up (the relationship between its portfolio $n^{A}$ and its equity $E$ ), the more attractive will be risk-shifting, and the smaller will be the switching point $\bar{n}^{A}$. So the comparative statics properties of $\bar{n}^{A}$ are in accordance with the literature on risk-shifting incentives, going back to Jensen and Meckling (1976).

The formal analysis (which is relegated to the Appendix) proceeds along the following lines. Assume that $n^{A} \geq \frac{1}{2}$. Then, with cherry-picking and no failure risk, the bank's profit is independent of the portfolio size, since the interest factor remains unchanged at $R=2$ (the marginal project picked up by an outside lender is a risky one). With risk-shifting, the bankruptcy probability is always positive, explaining why the profit is increasing in $n^{A}$. So there must be a unique threshold $\bar{n}^{A}$, and it must exhibit the desired properties. An analogous argument, comparing the slope of the profit functions under cherry-picking and risk-shifting, extends to the case $n^{A}<\frac{1}{2}$.

Finally, we can derive a closed-form expression for the threshold $\bar{n}^{A}$ from the condition that the profits from cherry-picking and from risk-shifting must be equal at this point. The profits from cherry-picking are given in Eq. (4.2), and the profits from risk-shifting can be obtained from Eq. (4.7) by setting $\alpha=1$ :

$$
\Pi_{r}^{A}=\left(1-\tilde{t}^{A}\right)\left(E\left[t \mid t>\tilde{t}^{A}\right] R n^{A}+E-n^{A}\right)
$$

After substituting the bankruptcy threshold $\tilde{t}^{A}$ in Eq. (4.3) and substituting the corresponding threshold in the case of risk-shifting in Eq. (4.8), which is simply:

$$
\tilde{t}^{A}=\frac{n^{A}-E}{R n^{A}},
$$

we can derive the switching point as (we show this in the proof of Lemma 2):

$$
\bar{n}^{A}=\frac{(2 E+2 k-1)^{\frac{1}{2}}-E+k-1}{(2 k-1)} .
$$

\subsection{Basel II: Optimal Loan Portfolio Size}

Based on the two last subsections, we can now ask how many projects the regulator will allocate to the IRB-bank, thereby taking into account that the risk-shifting incentive is increasing in $n^{A}$. We identify three different regions depending on the values of the parameters $k$ and $E$, and their impact on Bank A's incentives: 
Proposition 3. Suppose Bank A invests and is regulated as an IRB-bank. Then, the regulator's optimal choice of Bank $A$ 's portfolio size depends on the parameters $k$ and $E$ as follows: (i) Region 1: If $\bar{n}^{A} \geq E+k$, then the regulator sets $n^{A}=E+k$, Bank $A$ opts for cherry-picking and will be safe. $\bar{n}^{A} \geq E+k$ holds if $k$ and $E$ are sufficiently large such that $E \geq \frac{(1-k)^{2}}{2 k^{2}}-\left(k-\frac{1}{2}\right)$. (ii) Region 2: If $\frac{1}{2} \leq \bar{n}^{A}<E+k$, the regulator implements $n^{A}=\bar{n}^{A}$, Bank $A$ opts for cherry-picking and will be risk-free. $\bar{n}^{A} \geq \frac{1}{2}$ holds if $k$ and $E$ are sufficiently large such that $k \geq \frac{5}{8}-\frac{E(1-E)}{2}$. (iii) Region 3: Finally, if $\bar{n}^{A}<\frac{1}{2}$, the regulator either implements $n^{A}=\bar{n}^{A}$ such that Bank $A$ opts for cherry-picking, or $n^{A}=\bar{n}^{A}+\varepsilon$ such that Bank A opts for risk-shifting. Cherry-picking by Bank $A$ will be optimal for relatively large values of $k$ and $E$, and risk-shifting for small values of $k$ and $E$.

Proof. See Appendix.

Proposition 3 divides the parameter space in three regions which are illustrated in Figure 2. Region 1 refers to the situation where risk-shifting does not constitute a constraint on the portfolio size, as even with the optimal loan volume Bank $A$ will prefer safe projects. Accordingly, the capital adequacy requirement $b$ will be adjusted such that Bank $A$ can exactly fund the number of projects that avoids any bankruptcy risk, $n^{A}=k+E$. Bank $A$ will be the larger bank since $E+k>\frac{1}{2}$. This "too big to fail" result to banking regulation has already been presented (see Proposition 2).

Region 2 of Proposition 3 encompasses intermediate values of $k$ and $E$. Bank $A$ would adopt risk-shifting if the regulator implemented $n^{A}=E+k$, but it is still possible to allocate the larger portfolio to Bank $A\left(n^{A} \geq \frac{1}{2}\right)$ without provoking risk-shifting. It is easy to see when this is the case: Setting $\bar{n}^{A} \geq \frac{1}{2}$ in Eq. (4.10) and solving, we find that $\bar{n}^{A} \geq \frac{1}{2}$ if and only if $k \geq \frac{5}{8}-\frac{E(1-E)}{2}$. There can only be two possible optima in this case: either the regulator implements the maximum loan portfolio size for Bank $A$ that falls just short of the risk-shifting barrier $\bar{n}^{A}$. Or she chooses $n^{A}>\bar{n}^{A}$, with the consequence that Bank $A$ will select all risky projects. In either case, Bank $A$ will be the larger bank. As shown in the Appendix, the best choice for the regulator is indeed to give Bank $A$ the maximum allocation that avoids risk-shifting, $\bar{n}^{A}$. The shelter effect offers a good intuition: Since Bank $A$ is the larger bank, the loss for society given default will be smaller if the bankruptcy risk is allocated to the small bank and not the large bank.

For small values of $k$ and $E$, the situation is described by Region 3. This is probably the most interesting region since Bank $A$ will always be the smaller bank, contrary to the intuition that 
IRB-banks will have a stronger competitive position, and also contradicting the stated intention of the Basel Committee to offer lower capital standards for IRB banks. In fact, the problem is that making Bank $A$ the larger bank will inevitably lead to risk-shifting. As a consequence, the regulator will prefer to let the IRB-bank be the smaller one. Moreover, if risk-shifting incentives are very high, then the regulator may be better off to accommodate Bank $A$ 's risk-shifting, and still designate Bank $A$ as the smaller bank. Essentially, the reason is that Bank $A$ 's loan portfolio has then become so small that leaving the entire burden of risky projects to Bank $B$ means exposing it to a disproportionate bankruptcy risk. It is then better to share the bankruptcy risk between both banks.

\subsection{Hidden Investments in Internal Rating Systems}

There is another interesting aspect of Region 3. As seen in Proposition 3, the regulator will then designate Bank $A$ as the smaller bank, by restricting its portfolio size to $n^{A}=\bar{n}^{A}<\frac{1}{2}$. In other words, Bank $A$ will be penalized when it submits its IRS for approval to the regulator. But since this will be anticipated by Bank $A$, the bank will consider whether it really should apply for the status of an IRB-bank. If Bank $A$ "hides" the fact that it has developed an IRS, the regulator has no choice but to apply the capital adequacy requirements of a SA-bank, which, as we saw in Section 3, guarantees a portfolio of size $n_{u}=\frac{1}{2}$ to Bank $A$. So this is a rather attractive option, and we can easily verify that Bank $A$ will always prefer it. Namely, for any regulatory policy of $n^{A}<\bar{n}^{A}<\frac{1}{2}$, Bank $A$ 's profits will be strictly increasing in $n^{A}$. For $n^{A}>\bar{n}^{A}$, Bank $A$ will adopt risk-shifting, as it will do when it "hides" its investment and gets an allocation of $n_{u}=\frac{1}{2}$. So the last option must yield a strictly larger profit to Bank $A$ than any regulation leading to $n^{A}<\frac{1}{2}$. As a consequence, Bank $A$ will hide its investment and fund all of the risky projects, while Bank $B$ finances all safe projects.

After substituting Eq. (4.9) into Eq. (4.8), and using $n^{A}=\frac{1}{2}$ and $R=\frac{1}{k}$ (which will prevail in an equilibrium with risk-shifting), we can determine Bank $A^{\prime}$ 's profits as $\Pi_{r}^{A}\left(\frac{1}{2}\right)=$ $k\left(\frac{1}{2 k}+E-\frac{1}{2}\right)^{2}$, and total bankruptcy costs as $Z_{r}\left(\frac{1}{2}\right)=\frac{1}{4} z+\frac{1}{2} k z-\frac{7}{3} k z E$. We can then see why it can be profitable for Bank $A$ to invest even if it knows that the best strategy ex post is to hide its IRS capabilities. The gain from being able to engage in risk-shifting on a portfolio of size $\frac{1}{2}$, compared with earnings of $\Pi_{u}=\frac{(1+2 E(1+2 k))^{2}}{8(1+2 k)}$ that the bank will obtain when it does not invest (see Proposition 1), may outweigh the investment $\operatorname{cost} C$ if the latter is sufficiently low.

Naturally, this scenario is alarming for the regulator. We have seen in Proposition 3 that 
once Bank $A$ has invested, the socially optimal portfolio size is $n^{A}=\bar{n}^{A}<\frac{1}{2}$ in Region 3 (which may or may not lead to risk-shifting). Clearly, the aggregated bankruptcy loss in the case of a hidden IRS-investment, $Z_{r}\left(\frac{1}{2}\right)$, is higher than under the optimal allocation, $Z_{r}\left(\bar{n}^{A}\right)$. Comparing $Z_{r}\left(\frac{1}{2}\right)$ to $Z_{u}$ in expression (3.7), it turns out that the overall bankruptcy loss after a hidden IRS-investment is actually higher than in the Basel I benchmark case!

As we will see next, there is a simple defense for the regulator. The solution for the regulator will be to offer sufficiently large subsidies that will entice Bank $A$ to voluntarily submit its IRS to the regulator.

\section{Optimal Banking Regulation}

We can now close our analysis by moving backwards to the initial stage 1 of the game, where the regulator sets the stage by announcing its transfer policy, that is either a subsidy $s>0$ or a tax $s<0$. The transfer will take place if the bank has invested in IRS capabilities an submits them to the regulator to be licensed as an IRB-bank. We have just seen that one of the reasons why the regulator will offer subsidies is to make sure that the bank actually officially registers its IRS capabilities and will not hide them from the regulator. Another reason is that the investment criteria of regulator and Bank $A$ will often diverge, and subsidies or taxes for IRS-investments are a means to align the bank's decision with the social optimum. It should by now be clear that direct transfers $s$ strictly dominate any attempt to impose subsidies or taxes indirectly via an adjustment in the capital adequacy ratios $b$. The reason is that the regulator has a double objective: to create optimal investment incentives, and to ensure the optimal risk and loan portfolio allocation. It is obviously better to use the two instruments $s$ and $b$ to address each of these objectives separately, rather than to pursue both goals with the single policy instrument $b$, which inevitably leads to a conflict of objectives for the regulator.

Neglecting shadow costs of public funds, we make a simple utilitarian assumption for this analysis: the regulator uses public revenues for a subsidy but this will also boost the bank's net profit by the same amount, so the transfer is neutral in a welfare sense.

Let us then consider Bank $A$ 's incentive constraint. In view of our analysis in Section 4, it is clear that Bank $A$ will invest and submit its IRS if and only if

$$
\Pi^{A}-C+s \geq \max \left\{\Pi_{u}, \Pi_{r}^{A}\left(\frac{1}{2}\right)-C\right\}
$$

where $\Pi^{A}$ is Bank $A$ 's profit in the optimal regulation with investment in the three regions, 
and profits for Basel I $\left(\Pi_{u}\right)$ are as derived in Section 3. The regulator will fix the subsidy/tax $s$ at a level that aligns the bank's investment decision in stage 2 of the game with the social optimum.

For convenience, we introduce the following simple notation for the bankruptcy losses in equilibrium as they arise in the three subgames after Bank $A^{\prime}$ 's investment choice in stage 2 (see Figure 1): we define $Z_{i}=\min \left\{Z_{c}\left(\bar{n}^{A}\right), Z_{r}\left(\bar{n}^{A}\right)\right\}$ as total bankruptcy loss if Bank $A$ invests and applies to obtain IRB-status (Basel II), ${ }^{12}$ and $Z_{h}=Z_{r}\left(\frac{1}{2}\right)=\frac{1}{4} z+\frac{1}{2} k z-\frac{7}{3} k z E$ if it invests but hides its IRS. We define Bank $A$ 's profits $\Pi_{i}$ and $\Pi_{h}$ accordingly. For an equilibrium without investment (Basel I), bankruptcy costs $Z_{u}$ and bank profits $\Pi_{u}$ are given in expressions (3.7) and (3.5). The following Lemma summarizes the comparison of the bankruptcy losses after the different choices of Bank $A$ in stage 2, where we refer to the three regions in Figure 2:

Lemma 3. For the equilibrium bankruptcy losses in the game after Bank A's investment choice, we get $Z_{i} \leq Z_{h}$. In Region $1, Z_{i}<Z_{u}$. In Regions 2 and $3, Z_{i} \lessgtr Z_{u}$.

Proof. See Appendix.

This comparison provides the basis for the determination of the regulator's optimal overall policy. Lemma 3 expresses the regulator's preferences for the different investment choices: for the regulator, a choice by Bank $A$ to invest but hide its IRS will always be dominated, because $Z_{h}$ and $Z_{i}$ both refer to situations after costs of $C$ are invested. It follows immediately that whenever the bank would prefer to invest-and-hide, the regulator will take preemptive action and employ subsidies $s$ that are sufficient to satisfy incentive constraint (5.1) and will ensure that the Bank will submit its IRS capabilities for official approval. As we have seen, this happens in Region 3.

In Regions 1 and 2, for high and intermediate values of $k$ and $E$, the optimal Basel II regulation in the absence of risk-shifting is also better than a uniform banking sector (Basel I), at least as long as investment costs $C$ are ignored. There are two reasons for that: First, there is an interest rate effect. With a differentiated banking regulation (Basel II) and cherry-picking by Bank $A$, the interest rate is larger than in the uniform Basel I case, since the quality of the marginal project funded by a SA-bank is lower (the interest factors are $R=2$ and $R=\frac{4}{(1+2 k)}$, respectively). Higher profits make banks more stable, whereas the wealth distribution effect cancels out in the regulators' objective function. Thus, quality differentiation among banks serves as a convenient tool to reduce banking competition. Second, there is a risk and size differentiation effect. With a differentiated banking sector, the regulator can now use capital adequacy regulation to effectively

\footnotetext{
${ }^{12}$ As we saw in Proposition 3, the regulatory will then normally implement cherry-picking, but for low values of $k$ and $E$ may prefer risk-shifting. This explains the $\min \{$.$\} in the definition of Z_{i}$.
} 
differentiate the risk allocation and the portfolio size across banks. The number of safe projects picked up by the Bank $A$ effectively bolsters its equity, since all risk of these projects washes out as a portfolio diversification effect. In the optimal policy, only the small bank (which necessarily is Bank $B$ ) bears bankruptcy risk, not the large bank.

Interestingly, the superiority of the Basel II-regulation is increasing in $k$, but decreasing in $E$. As for the return parameter $k$ that measures the relative attractiveness of safe over risky projects, this effect is quite straightforward. In fact, the larger is $k$, the more important is the interest rate effect, and this will dominate all other effects in equilibrium. The fact that the advantage is decreasing in $E$ follows from two effects: first, under Basel I, both banks have a positive bankruptcy risk which is decreasing in $E$. And second, the lower the interest rate, the more important is the equity $E$ in order to reduce the failure risk. In fact, the difference in the marginal impact of $E$ on the uniform and the differentiated banking is increasing in $k$, because the interest rate in the uniform case is decreasing in $k$, while it is independent of $k$ in the differentiated case.

The opposite roles of $k$ and $E$ in the welfare comparison can also be explained when providing an intuition why, according to Lemma 3, in Regions 2 and 3 the bankruptcy loss may be smaller in the Basel I outcome than in the case where Bank $A$ invests, prefers cherry-picking and is allowed to finance $n^{A}=\min \left\{\bar{n}^{A}, k+E\right\}$ projects. This is, at first, a surprising observation: the interest rate and size differentiation effect would rather suggest the opposite. However, if $k$ is small, then $\bar{n}^{A}$ is relatively close to $\frac{1}{2}$, so neither size differentiation nor the interest rate effect which describes the variation of $R$ in the interval $\left(\frac{1}{k}, 2\right)$ - are very important. On the other hand, since Bank $A$ does not finance any risky projects, its equity $E$ is idling, i.e. it is not employed to absorb the portion of risk that the bank can assume without incurring any failure risk (any $n^{A} \leq E$ ), an inefficiency that is increasing in $E$. This intuition suggests that Basel I can be more attractive for the regulator than Basel II for small $k$ and relatively large equity endowments $E$.

The final question of our analysis is then whether it is always feasible for the regulator to implement the preferred allocation. The difficulty is that the preferences of Bank $A$ and the regulator may well differ. Consider Region 2 as an example. Then, we already know that $\Pi_{i}-\Pi_{u}>$ 0 as profits are increasing in $n^{A}$, so that an investment is always optimal for the bank for small investment costs $C$. On the other hand, we also know from Lemma 3 that total bankruptcy costs may be smaller in the Basel I outcome $\left(Z_{u}-Z_{i}<0\right)$, so that an investment is never desirable.

In general, for the regulator, the Basel II outcome is superior to Basel I when $Z_{u}-Z_{i} \geq C$, i.e. if investment costs yield a sufficient return in form of lower bankruptcy costs. Bank $A$, however, 
will only invest and submit for certification if incentive constraint (5.1) holds. We say that there is an overinvestment problem if $Z_{u}-Z_{i}<C \leq \max \left\{\Pi_{i}, \Pi_{h}\right\}-\Pi_{u}$, so that the bank would invest (safe for the remedial tax/subsidy $s$ that we will consider in a moment), whereas the regulator wouldn't. Conversely, we say that there is an underinvestment problem if $\Pi_{i}-\Pi_{u}<C \leq Z_{u}-Z_{i}$, so that the regulator wants to invest whereas the bank will not, unless it obtains subsidies when it does. Finally, we say that the preferences of the regulator are aligned if both $Z_{u}-Z_{i} \geq C$ and $\Pi_{i}-\Pi_{u} \geq C$ or $Z_{u}-Z_{i}<C$ and $\Pi_{i}-\Pi_{u}<C$ hold simultaneously. The decision on the subsidy/tax $s$ in stage 1 then leads to the following outcome in the overall equilibrium of the game:

Proposition 4. (i) In Regions 1 and 2, if preferences are aligned, then the outcome will be Basel II with $n^{A}=\min \left\{\bar{n}^{A}, k+E\right\}$ if $Z_{u}-Z_{i} \geq C$, and Basel I otherwise. There will be no tax or subsidy. If there is an underinvestment problem, then the outcome will be Basel II with $n^{A}=\min \left\{\bar{n}^{A}, k+E\right\}$, and there will be a subsidy of $s \geq C-\left(\Pi_{i}-\Pi_{u}\right)$. Finally, if there is an overinvestment problem, and if $C>\Pi_{h}-\Pi_{u}$, then the outcome will be Basel I and there will be a tax of $s \leq C-\left(\Pi_{h}-\Pi_{u}\right)<0$; if $C \leq \Pi_{h}-\Pi_{u}$, then the outcome will be Basel II with $n^{A}=\min \left\{\bar{n}^{A}, k+E\right\}$, and $s=0$.

(ii) In Region 3, if preferences are aligned or there is an overinvestment problem and if $Z_{u}-Z_{i} \geq$ $C$, there will be a subsidy of $s \geq \Pi_{h}-\Pi_{i}$, and the outcome will be Basel II with $n^{A}=\bar{n}^{A}<\frac{1}{2}$, and the outcome will be Basel I if $Z_{u}-Z_{i}<C$. If there is an underinvestment problem, then the outcome will be Basel II with $n^{A}=\bar{n}^{A}<\frac{1}{2}$, and there will be a subsidy of $s \geq C-\left(\Pi_{i}-\Pi_{u}\right)$.

Proof. See Appendix.

The first part of item (i) of the Proposition is straightforward. If the preferences are aligned, then Bank $A$ invests if and only if this is also socially beneficial, so that no subsidies or taxes are required to reach the optimum. Recall from Lemma 4 that this will always be Basel II if investment costs $C$ are sufficiently small and if there is no risk-shifting problem, i.e. if $n^{A}=E+k$ with cherry-picking is feasible. If this is not feasible, the outcome may be Basel II with cherry-picking or with risk-shifting, but it may also be Basel I with a uniform banking sector even for $C=0$.

The second part, concerning underinvestment, says that the regulator will always be in a position to implement Basel II if this is the best outcome. So together with the first part, this shows that the outcome will be Basel II whenever this is preferred by the regulator, regardless of Bank $A$ 's preferences. The reason is that by offering a high enough subsidy, the regulator can 
always induce the bank to invest and to obtain the certification as an IRB-bank. Hence, absent shadow costs of public funds, underinvestment problems can be perfectly addressed.

The final part of item (i) addresses overinvestment situations, which pose a somewhat more intricate problem. In principle, the regulator can deter an investment application by taxing an IRS at a sufficiently high rate. But then, Bank $A$ still has the option to invest and hide its IRS. This puts a cap on the maximum tax that is enforceable, and explains why the relevant comparison is now between Bank $A$ 's profit when it does not invest, $\Pi_{u}$, and its net profit when it invests and hides, $\Pi_{h}-C$. If the latter investment option yields a net profit below the profit with a uniform banking sector $\left(\Pi_{h}-C<\Pi_{u}\right),{ }^{13}$ then the regulator can indeed attain the optimum with a tax that will prevent Bank $A$ from making the investment. But if $\Pi_{h}-C \geq \Pi_{u}$, then the bank will invest anyway, and the regulator, anticipating investment, prefers the optimal solution $\bar{n}^{A}$ to $n^{A}=\frac{1}{2}$, will accommodate the overinvestment, and the outcome will again be Basel II with the optimal allocation $\bar{n}^{A}$.

The intuition for item (ii) of the Proposition is as follows. In Region 3, if Bank $A$ invests, it should optimally be designated as the smaller bank, $\bar{n}^{A}<\frac{1}{2}$. Therefore, it would normally hide its IRS from the regulator, which leads to a suboptimal portfolio and risk allocation as we had seen in Section 4.4. Therefore, the regulator will always prevent this outcome from occurring by offering a subsidy that entices Bank $A$ to become an IRB-bank if it invests. This explains why subsidies can be the optimal outcome even in case of an overinvestment situation.

In conclusion, underinvestment situations can always be remedied with subsidies, but the same does not hold for overinvestment problems. There are situations where Bank $A$ will invest anyway, notably to take advantage of risk-shifting opportunities, and the regulator has no choice but to set incentives to apply for a licence. Overinvestment problems are more likely to occur if risk-shifting incentives are high ( $k$ is small), banks are undercapitalized ( $E$ is small), or if the social cost of bankruptcy is small ( $z$ is small).

Thus, our analysis exposes a defensive side of the proposed Basel II Accord: faced with the prospect of advanced banks acquiring increasingly sophisticated screening capabilities, the best option for regulators is to accommodate this development in order to secure control over the allocation of risks within an increasingly differentiated banking sector. If many banks will rapidly embrace Basel II and receive regulatory approval to operate as IRB-banks, that does not mean that the process is socially optimal. It can simply be an expression of regulatory capture, or of

\footnotetext{
${ }^{13}$ Note that this is not excluded by the definition of an overinvestment problem as we may have $\Pi_{r}^{*}<\Pi_{c}^{*}$.
} 
a situation where it is impossible for regulators to keep pace with banks' increasingly advanced tools. In the same vein, if regulators find it optimal to grant subsidies for banks willing to invest to be ready for the IRB-approach, that does not mean that the IRS-investment is socially optimal.

\section{Discussion and Conclusion}

The purpose of this paper is to analyze a particular aspect of the proposed Basel II Accord, namely the intention to differentiate between banks that use internal ratings and banks that use the standard approach. We investigate general equilibrium effects of this proposal in a simple model where one of the banks has the opportunity to invest and get approval for the use of internal ratings.

Absent risk-shifting incentives, we find that the regulator will assign lower risk-adjusted capital requirements to the internal ratings bank (IRB-bank), and increase its market share. We argue that the differentiation under the Basel II Accord will affect welfare through two distinct channels, an interest rate effect (the anticompetitive effect of higher interest rates if banks become more heterogenous) and a size and risk differentiation effect, which refers to economies of scale in the absorption of bank failure risk. This effect implies that welfare generally increases if failure risk is allocated asymmetrically across banks, and if the risky banks are put at a regulatory disadvantage. This allows safe bank to gain market share and hence shelter a larger fraction of the overall loan portfolio from failure risk. Interest rate and size differentiation effect both favor the differentiation among banks proposed by the Basel Committee, and hence we find a positive welfare impact of the proposal if investment costs in more advanced internal ratings system are small.

But the picture becomes more intricate when we consider that IRB-banks can use their informational advantage to manipulate the riskiness of their loan portfolios and to engage in riskshifting. We find that, when risk-shifting incentives are strong, then the interest rate effect and the differentiation effect become less and less important, and may eventually be overshadowed by the inefficient risk absorption of the safe bank. Then, the regulator should curtail the lending of IRB-banks so much that they are at a competitive disadvantage compared with SA-banks.

The regulator will use monetary incentives to align the investment incentives of banks with the social optimum that takes account of externalities and contagion effects linked to bank failure. We find that lump-sum transfers will strictly dominate any policy of handing out subsidies indirectly via lower capital adequacy ratios. The reason is that the regulator pursues two different objectives, to align investment incentives and to control the optimal portfolio allocation across banks, and 
that she needs two separate policy instruments to avoid conflicts. The regulatory can usually avoid underinvestment problems, but is frequently forced to accommodate situations where banks inefficiently overinvest into their internal ratings system. Massive adoption of the IRB-approach is, therefore, not synonymous to a welfare improvement.

Our analysis helps to identify several aspects that merit close regulatory attention: first, the loan portfolio quality of banks using the standard approach will generally worsen, as a result of the cherry picking by sophisticated banks. Second, internal rating banks may be inclined to manipulate their portfolios and to take on excessive risks. Third, the investment incentives of banks to foster their internal ratings systems will normally not be aligned with the socially preferred outcome, and overinvestment will occur. Finally, this problem is likely to be exacerbated if there are conflicts of interest whether banks will truthfully disclose the full extent of their knowledge in internal rating models and risk calculation models.

Our model is certainly stylized, but its simple structure has the merit to analyze the consequences for bank stability, financial market structure, lending rates ad social efficiency in a single coherent framework that allows to distinguish between the private and the social implications of bank activity. A few of our simplifying assumptions merit some discussion. First, when analyzing the regulator's policy of subsidies or tax levies on IRB-banks, we made the utilitarian assumption that any such transfer is neutral from a welfare point of view. This is certainly not realistic as there are usually shadow costs associated with the use of public funds. While we believe that this is important, we chose to omit it since it would complicate our analysis considerably without adding much from an analytical point of view. Suppose that one euro in subsidies costs $\lambda>1$ euros if financed by taxes. Then, a subsidy will be granted only if $Z_{u}-Z_{i} \geq C+\lambda s$. This has no important impact on the qualitative essence of our findings, but would force us to distinguish additional cases.

Second, concerning the returns and return correlations of projects, our maintained assumption in the analysis is that safe projects also yield higher expected returns. At first glance, this assumption seems to contradict the usual relation between risk and return on financial markets. But notice that our assumption merely reflects the well-known perverse incentives in banks' portfolio selection: banks with positive bankruptcy risk and no regulation usually have strong incentives to increase the systematic risk in their portfolio if it does not hurt their expected return (see e.g. Acharya, 2001). In an equilibrium market model, therefore, the factor premium for systematic risk should be negative. For assets with high systematic risk, banks should on average charge a lower interest rate. We model this insight by assuming that correlated projects have, for identical 
interest rates, a lower success probability.

From our discussion in Section 4.3, it is now straightforward to see what happens if $k<\frac{1}{2}$ : it would just be an extension of the case $k \searrow \frac{1}{2}$ that we analyzed in Proposition 3 and following. Risk-shifting would become unavoidable if bank $A$ adopts an internal rating system, but the regulator would like to avoid risk-shifting as often as possible. As a consequence, adopting the dual approach that Basel II proposes and allowing banks to adopt and use their own rating systems will lead to an efficiency loss compared with the status quo, which corresponds to a uniform banking sector.

Third, we assumed that bankruptcy losses nz are linear. The linearity ensures the formal tractability and closed form characterization of our analysis. Recall that $z$ captures the social losses of bank failure, due to disruption in the financial system and financial fragility, and it seems natural to assume that these losses are increasing in the size of the failed bank. We do not have a strong view whether a neoclassical assumption of convex bankruptcy losses, or rather concave costs reflecting some economies of scale in the social response to a bank's failure would be the natural extension, and so the linear case may be viewed as a compromise between these two conflicting views. As long as bankruptcy losses are assumed to be increasing (convex linear, or concave), the qualitative message of our model should go through.

Finally, our model expressed a strong view on the superior screening capacity of high banks which have perfect information about the credit risk associated with each project while SA-banks and regulators can share none of it. Again, this is a simplifying assumption. The important element is merely that there is an information differential between IRB-banks on the one hand, and regulators on the other, that banks can exploit opportunistically. As long as this is the case, there is reason to be concerned about the problems that we identify, namely the deterioration of the project pool for SA-banks and the risk-shifting problem. 


\section{References}

[1] Acharya, V.V. (2001) A Theory of Systemic Risk and Design of Prudential Bank Regulation, Working Paper, New York University.

[2] Acharya, V.V. (2003) Is the International Convergence of Capital Adequacy Ratios Desirable? Journal of Finance, 58, 27-45.

[3] Allen, L. (2004) The Basel Capital Accords and International Mortgage Markets: A Survey of the Literature, Financial Markets, Institutions and Instruments, 13, 41-108.

[4] Altman, E.I. and Saunders, A. (2001) An analysis and critique of the BIS proposal on capital adequacy and ratings, Journal of Banking and Finance, 25, 25-46.

[5] Basel Committee on Banking Supervision (2004) International Convergence of Capital Measurement and Capital Standards. A Revised Framework, Bank for International Settlements, June 2004.

[6] Besanko, D. and G. Kanatas (1996) The Regulation of Bank Capital: Do Capital Standards Promote Bank Safety? Journal of Financial Intermediation, 5, 160-183.

[7] Bhattacharya, S., Boot, A.W.A. and Thakor, A. V. (1998) The Economics of Bank Regulation, Journal of Money, Credit, and Banking, 30, 745-770.

[8] Boot, A.W.A. and Greenbaum, S.I. (1993) Bank regulation, reputation and rents: theory and policy Implications, in: Mayer, C.; Vives, X. (ed.) Capital Markets and Financial Intermediation, Cambridge University Press, Cambridge, 262-285.

[9] Calem, P. and R. Rob (1999) The Impact of Capital-Based Regulation on Bank Risk-Taking, Journal of Financial Intermediation, 8, 317-352.

[10] Carey, M. (2001) Some Evidence on the Consistency of Banks' Internal Credit Ratings, mimeo, Federal Reserve Board.

[11] Claessens, S. and G. Embrechts (2003) Basel II, Sovereign Ratings and Transfer Risk. External versus Internal Ratings. mimeo, University of Amsterdam/World Bank.

[12] Dangl, T. and Lehar, A (2002) Value-at-Risk Regulation vs. Building Block Regulation in Banking, Working Paper, University of Vienna. 
[13] Decamps, J.P., Rochet, J.C., and Roger, B. (2004) The Three Pillars of Basel II: Optimizing the Mix, Journal of Financial Intermediation, 13, 132-155.

[14] Furfine, C. (2001) Bank Portfolio Allocation: The Impact of Capital Requirements, Regulatory Monitoring, and Economic Conditions, Journal of Financial Services Research, 20, 33-56.

[15] Gersbach, H. and Wehrspohn, U. (2001) Lean IRB Approaches and Transition Design: The Basel II Proposal, Working Paper, University of Heidelberg.

[16] Gropp, R. and A.J. Richards (2001) Rating Agency Actions and the Pricing of Debt and Equity of European Banks: What Can We Infer About Private Sector Monitoring of Bank Soundness? European Central Bank Working Paper Series No. 76.

[17] Hellmann, T.F., Murdock, K.C. and Stiglitz, J.E. (2000) Liberalization, Moral Hazard in Banking and Prudential Regulation: Are Capital Requirements Enough ? American Economic Review, 90, 147-165.

[18] James, C. (1987) Some Evidence on the Uniqueness of Bank Loans, Journal of Financial Economics, 19, 217-235.

[19] Jensen, M. and Meckling, W. (1976) Theory of the Firm: Managerial Behavior, Agency Costs and Ownership Structure, Journal of Financial Economics, 3, 305-360.

[20] Marshall, S. and Venkatamaran, S. (1999) Bank Capital Standards for Market Risk: A Welfare Analysis, European Finance Review, 2, 125-157.

[21] Matutes, C. and Vives, X. (1996) Competition for Deposits, Fragility, and Insurance, Journal of Financial Intermediation, 5, 184-216.

[22] Montfort, B. and Mulder, C. (2000) Using Credit Ratings for Capital Requirements on Lending to Emerging Market Economies: Possible Impact of a New Basel Accord, IMF Working Paper WP/00/69, Washington, DC.

[23] Morrison, A.D. and White, L. (2004), Crises and Capital Requirements in Banking, CEPR Discussion Paper 4364

[24] Peura, S. and Jokivuolle, E. (2001) Simulation-based stress testing of banks' regulatory capital adequacy, Journal of Banking and Finance, 28, 1801-1824. 
[25] Repullo, R. (2002) Capital Requirements, Market Power, and Risk Taking in Banking, Working Paper, CEMFI.

[26] Repullo, R. and J. Suarez (2003) Loan Pricing Under Basel Capital Requirements, CEPR Discussion Paper 3917.

[27] Santos, J. (2001) The Regulation of Bank Capital: A Review of the Theoretical Literature, Financial Markets, Institutions and Instruments,10, 41-84.

[28] Thakor, A.V. (1996) Capital Requirements, Monetary Policy, and Aggregate Bank Lending: Theory and Empirical Evidence, Journal of Finance, 51, 279-324. 


\section{Appendix}

Proof of Proposition 1. We first need to show that the optimal $n_{u}$ is either $n_{u}=E(1+2 k)$ or $n_{u}=\frac{1}{2}$. Taking the partial derivative of $W_{u}$ yields

$$
\frac{\partial W_{u}}{\partial n_{u}}=\frac{1}{2} X+X k-2-z
$$

Hence, $W_{u}$ is linear in $n_{u}$. If $\frac{1}{2} X+X k-2-z>0$, total welfare is strictly increasing in $n_{u}$, which means that the regulator allows for all projects. Otherwise, the regulator chooses $b_{u}$ such that the bankruptcy risk is zero, which is the case for $n_{u} \leq E(1+2 k)$.

Proof of Proposition 2. In Proposition 2, we restrict attention to $n^{A} \geq \frac{1}{2}$. Let $Z_{c}^{A}\left(Z_{c}^{B}\right)$ be the bankruptcy loss from Bank $A$ (Bank $B$ ). We take the expression of total social costs of bank failure $Z_{c}$ in Eq. (4.6) and substitute $\tilde{t}^{A}$ from Eq. (4.3) and $\tilde{t}^{B}$ from eq. (4.5). This yields:

$$
Z_{c}=Z_{c}^{A}+Z_{c}^{B}=\frac{n^{A}-E-k}{2 n^{A}-1} n^{A} z+\frac{1-n^{A}-E}{2} z .
$$

Taking the derivative w.r.t. $n^{A}$ gives

$$
\frac{\partial Z_{c}}{\partial n^{A}}=\frac{1}{2\left(2 n^{A}-1\right)} z(2 E+2 k-1)>0 .
$$

This proves that $Z_{c}$ is increasing in $n^{A}$ if $n^{A}>k+E$, i.e. if Bank $A$ faces a positive bankruptcy risk. Otherwise, if only Bank $B$ may go bankrupt, total bankruptcy costs are simply

$$
Z_{c}=Z_{c}^{B}=\frac{1-n^{A}-E}{2} z
$$

as $Z_{c}^{A}=0$. It follows that

$$
\frac{\partial Z_{c}^{B}}{\partial n^{A}}=-\frac{1}{2} z<0
$$

Since $\frac{\partial Z_{c}}{\partial n^{A}}>0$ if $n^{A}>k+E$ and $\frac{\partial Z_{c}}{\partial n^{A}}<0$ if $n^{A}<k+E$, it is optimal to implement $n^{A}=k+E$. We also clearly have that total bankruptcy costs are decreasing in $n^{A}$ for all $n^{A}<\frac{1}{2}$ (a formal proof follows the argument in Proposition 3 for the case $n^{A}<\bar{n}^{A}$ ). Total bankruptcy costs as stated in the Proposition follow immediately from substituting $n^{B}=1-n^{A}=1-E-k$ in Bank $B$ 's bankruptcy costs, and from taking into account that $Z_{c}^{A}=0$.

Proof of Lemma 1. Recall that $\alpha$ is the percentage of risky projects in the bank's portfolio. Hence, as a function of $\alpha$, the profit is given by:

$$
\Pi^{A}=\left(1-\tilde{t}^{A}\right)\left((1-\alpha) k R n^{A}+\alpha E\left[t \mid t \geq \tilde{t}^{A}\right] R n^{A}+E-n^{A}\right) .
$$


The bankruptcy threshold is thus:

$$
\tilde{t}^{A}=\max \left(\frac{n^{A}-E-k R n^{A}(1-\alpha)}{\alpha R n^{A}}, 0\right) .
$$

Eq. (A.6) defines a threshold value of $\alpha=\bar{\alpha}$ such that $\tilde{t}^{A}=0$ for all $\alpha \leq \bar{\alpha}$ and $\tilde{t}^{A}>0$ for all $\alpha>\bar{\alpha}$. Note that $\alpha \leq \bar{\alpha}$ is feasible for all values of $n^{A} \leq k+E$. Hence:

$$
E\left[t \mid t \geq \tilde{t}^{A}\right]=\max \left(\frac{1}{2}, \frac{R n^{A}(\alpha-k+k \alpha)-E+n^{A}}{2 \alpha R n^{A}}\right) .
$$

Substituting for $E\left[t \mid t \geq \tilde{t}^{A}\right]$ in Eq. (A.5), profits can be rewritten as:

$$
\Pi^{A}=\left\{\begin{array}{cc}
(1-\alpha) n^{A} k R+\alpha n^{A} \frac{1}{2} R+E-n^{A} & \text { if } \tilde{t}^{A}=0 \\
\frac{\left(\alpha R n^{A}+k R n^{A}(1-\alpha)+E-n^{A}\right)^{2}}{2 \alpha R n^{A}} & \text { if } \tilde{t}^{A}>0
\end{array} .\right.
$$

For $\alpha \leq \bar{\alpha}, \tilde{t}^{A}=0$. As we would expect, profits are strictly declining in $\alpha$ as long as $\alpha<\bar{\alpha}$,

$$
\left.\frac{\partial \Pi^{A}}{\partial \alpha}\right|_{\alpha<\bar{\alpha}}=n^{A} R\left(\frac{1}{2}-k\right)<0
$$

If bankruptcy is possible $(\alpha>\bar{\alpha})$, we get

$$
\left.\frac{\partial \Pi^{A}}{\partial \alpha}\right|_{\alpha>\bar{\alpha}}=-\frac{1}{8 \alpha^{2} R n^{A}}\left(\left(2 k R n^{A}+2 E-2 n^{A}\right)^{2}-\left((2-2 k) R n^{A} \alpha\right)^{2}\right) .
$$

The second derivative is:

$$
\left.\frac{\partial^{2} \Pi^{A}}{\partial \alpha^{2}}\right|_{\alpha>\bar{\alpha}}=\frac{1}{4} \frac{4 E^{2}-8 E n^{A}+4\left(n^{A}\right)^{2}+4 k^{2} R^{2}\left(n^{A}\right)^{2}-8 k R\left(n^{A}\right)^{2}+8 k R n^{A} E}{\alpha^{3} R n^{A}} .
$$

Now $\frac{\partial^{2} \Pi^{A}}{\partial \alpha^{2}}>0$ if the numerator is positive. We will show that the numerator is strictly positive for all feasible values of $R, R \in\left[\frac{1}{k}, 2\right]$. Note that:

$$
\begin{aligned}
& \frac{\partial(\cdot)}{\partial R}\left(4 E^{2}-8 E n^{A}+4\left(n^{A}\right)^{2}+4 k^{2} R^{2}\left(n^{A}\right)^{2}-8 k R\left(n^{A}\right)^{2}+8 k R n^{A} E\right) \\
& =8 k^{2} R\left(n^{A}\right)^{2}-8 k\left(n^{A}\right)^{2}+8 k n^{A} E>0 .
\end{aligned}
$$

Hence it is sufficient to show that $\frac{\partial^{2} \Pi^{A}}{\partial \alpha^{2}}>0$ for the minimum $R \equiv R^{\text {min }}=\frac{1}{k}$. Substituting $R^{\text {min }}$ in the numerator of (A.11) yields:

$$
\frac{\partial^{2} \Pi^{A}\left(R^{\min }\right)}{\partial \alpha^{2}}=4 E^{2}>0
$$


Hence $\Pi^{A}$ is continuous and globally convex, strictly decreasing for all $\alpha<\bar{\alpha}$ and strictly convex for all $\alpha>\bar{\alpha}$, implying that $\Pi^{A}$ has no interior maximum.

\section{Proof of Lemma 2.}

We begin with the following Lemma that allows us to restrict our proof to the properties of $\bar{n}^{A}$ :

Lemma 4. There can be at most a single threshold $\bar{n}^{A}$ where Bank $A$ switches from cherrypicking to risk-shifting.

Proof of Lemma 4. First, consider the case where $n^{A} \in\left(\frac{1}{2}, k+E\right)$. Profits with cherry-picking are:

$$
\Pi_{c}^{A}=\frac{1}{2} k R+\left(n^{A}-\frac{1}{2}\right) \frac{1}{2} R+E-n^{A}
$$

as the bank faces no bankruptcy risk. For profits with risk-shifting, by using the profit expression from the proof of Lemma 1 and taking into account that with risk-shifting we have $\alpha n^{A}=\frac{1}{2}$, it follows:

$$
\Pi_{r}^{A}=\frac{\left(\frac{1}{2} R+k R\left(n^{A}-\frac{1}{2}\right)+E-n^{A}\right)^{2}}{R} .
$$

Let $\Delta \Pi^{A}=\Pi_{c}^{A}-\Pi_{r}^{A}$ denote the profit difference. From Lemma 1, we know that in equilibrium there will be either cherry-picking or risk-shifting, so either $R=2$ or $R=\frac{1}{k}$. Thus, it is sufficient to show that, for either of these two values of $R$ :

$$
\frac{\partial \Delta \Pi}{\partial n^{A}}=\frac{\partial\left(\Pi_{c}^{A}-\Pi_{r}^{A}\right)}{\partial n^{A}}<0
$$

such that the profit difference is indeed decreasing in $n^{A}$. Now

$$
\frac{\partial \Delta \Pi^{A}}{\partial n^{A}}=\frac{1}{2} R+\frac{1}{R}\left(-2 n^{A}+2 E\right)-k+4 k n^{A}-2 k E+R\left(k^{2}-k-2 k^{2} n^{A}\right) .
$$

If $R=2$, we get:

$$
\frac{\partial \Delta \Pi^{A}}{\partial n^{A}}=-(2 k-1)\left(E-n^{A}-k+2 k n^{A}+1\right)<0,
$$

and if $R=\frac{1}{k}$, we get:

$$
\frac{\partial \Delta \Pi^{A}}{\partial n^{A}}=-2 k n^{A}+2 k E+2 n^{A}-2 E-\frac{1}{2 k}<0,
$$

showing the claim. 
Second, consider $n^{A}>k+E$. In this case, Bank $A$ will no longer be defaultfree when cherrypicking, and hence we get as profit expression in the cherry-picking case:

$\Pi_{c}^{A}=\left(1-\tilde{t}^{A}\right)\left(\frac{1}{2} k R+\left(n^{A}-\frac{1}{2}\right) E\left[t \mid t \geq \tilde{t}^{A}\right] R+E-n^{A}\right)=\frac{\left(2 E-R+R k-2 n^{A}+2 R n^{A}\right)^{2}}{4\left(2 n^{A}-1\right) R}$.

As the residual project is risky, we have $R=2$ and thus

$$
\Pi_{c}^{A}=\frac{\left(E-1+k+n^{A}\right)^{2}}{\left(2 n^{A}-1\right)} .
$$

Taking the derivative yields:

$\frac{\partial}{\partial n^{A}}\left(\frac{\left(E-1+k+n^{A}\right)^{2}}{\left(2 n^{A}-1\right)}\right)=2\left(\frac{1}{2 n^{A}-1}\left(k+n^{A}+E-1\right)\left(1-\frac{1}{2 n^{A}-1}\left(k+n^{A}+E-1\right)\right)\right)<0$.

On the other hand, for the profit in the risk-shifting case, the derivative is:

$$
\begin{aligned}
\frac{\partial \Pi_{r}^{A}}{\partial n} & =\frac{\partial}{\partial n^{A}}\left(\left(1+2 k\left(n^{A}-\frac{1}{2}\right)+E-n^{A}\right)^{2}\right) \\
& =2(2 k-1)\left(E-n^{A}-k+2 k n^{A}+1\right)>0 .
\end{aligned}
$$

Taking together, this shows again that $\frac{\partial \Delta \Pi^{A}}{\partial n^{A}}<0$.

Third, consider the case $\bar{n}^{A}<\frac{1}{2}$. Bank $A$ will again choose cherry-picking iff $\Pi_{c}^{A} \geq \Pi_{r}^{A}$, which for $n^{A}<\frac{1}{2}$ gives:

$$
n^{A} k R+E-n^{A} \geq\left(n^{A} E[t \mid t>\tilde{t}] R+E-n^{A}\right)\left(1-\tilde{t}^{A}\right) .
$$

The switching point $\bar{n}^{A}<\frac{1}{2}$ is given by equality in (A.19). Using $E\left[t \mid t>\tilde{t}^{A}\right]\left(1-\tilde{t}^{A}\right)=$ $\frac{1-\left(\tilde{t}^{A}\right)^{2}}{2}$ and $\tilde{t}^{A}=\frac{n^{A}-E}{n^{A} R}$, Inequality (A.19) can be written as:

$$
n^{A} R\left(k-\frac{1}{2}+\frac{\left(n^{A}-E\right)^{2}}{2\left(n^{A} R\right)^{2}}\right) \geq \frac{\left(n^{A}-E\right)^{2}}{n^{A} R}
$$

hence

$$
\left(n^{A} R\right)^{2}(2 k-1) \geq\left(n^{A}-E\right)^{2} .
$$

Introducing equality in (A.20), taking roots on both sides and defining

$$
x=\frac{1}{\sqrt{2 k-1}}
$$


yields $\bar{n}^{A}<\frac{1}{2}$, the maximum lending where Bank $A$ will be cherry-picking in equilibrium, as:

$$
\bar{n}^{A}=\frac{x}{x-R} E .
$$

Finally, we observe that, as the equilibrium switches from cherry-picking to risk-shifting, the equilibrium interest factor $R$ adjusts downwards in all three regions of $\bar{n}^{A}$. Thus, our assumption on market beliefs (footnote 6) rules out any ambiguity about the switching point: $\bar{n}^{A}$ is the maximum lending level where cherry-picking is sustainable for $R$ corresponding to a cherry-picking equilibrium, and for any $n^{A}>\bar{n}^{A}$, risk-shifting (with the associated lower $R$ ) is an equilibrium.

Given Lemma 4, we can now derive a closed expression for $\bar{n}^{A} \geq \frac{1}{2}$ as stated in the text. As $\bar{n}^{A}$ is the maximum lending level where Bank $A$ chooses cherry-picking, we have $R=2$. Substituting into the profit expression yields for any $n^{A} \leq k+E$ :

$$
\Pi_{c}^{A}=E+k-\frac{1}{2}
$$

which is independent of $n^{A}$ as risky projects just break even. If Bank $A$ deviated to riskshifting, then still $R=2$, and from (A.15) we have:

$$
\Pi_{r}^{A}=\frac{1}{2}\left(E-n^{A}+k\left(2 n^{A}-1\right)+1\right)^{2} .
$$

Since $\bar{n}^{A}$ is defined as the point where $\Pi_{r}^{A}=\Pi_{c}^{A}$, it follows

$$
\frac{1}{2}\left(E-n^{A}+k\left(2 n^{A}-1\right)+1\right)^{2}=E+k-\frac{1}{2},
$$

which we can solve as:

$$
\bar{n}^{A}=\frac{(2 E+2 k-1)^{\frac{1}{2}}-E+k-1}{(2 k-1)}
$$

as stated in the text, and which gives us

$$
\bar{n}^{A} \lesseqgtr \frac{1}{2} \Leftrightarrow k \lesseqgtr \frac{5}{8}-\frac{E(1-E)}{2} .
$$

Furthermore, note that the bank strictly prefers risky projects for $k=\frac{1}{2}$ as

$$
\Pi_{c}^{A}-\Pi_{r}^{A}=\left(k+E-\frac{1}{2}\right)-\frac{\left(1+2 k n^{A}-k+E-n^{A}\right)^{2}}{2},
$$

and hence 


$$
\Pi_{c}^{A}-\Pi_{r}^{A}\left(k=\frac{1}{2}\right)=-\frac{1}{2} E^{2}+\frac{1}{2} E-\frac{1}{8}<0 .
$$

It remains to show that $\bar{n}^{A}$ is monotonic in $k$ and $E$.

Consider first $\bar{n}^{A} \geq \frac{1}{2}$. We take the expression for $\bar{n}^{A}$ in (A.22) and analyze the derivative with respect to $k$ :

$$
\begin{aligned}
& \frac{\partial}{\partial k}\left(\frac{(2 E+2 k-1)^{\frac{1}{2}}-E+k-1}{(2 k-1)}\right) \\
& =\frac{1}{2 k-1}\left(\frac{1}{\sqrt{2 k+2 E-1}}+1\right)+\frac{2}{(2 k-1)^{2}}(E-k-\sqrt{2 k+2 E-1}+1)
\end{aligned}
$$

A sufficient condition for this expression to be positive is:

$$
\frac{(\sqrt{2 k+2 E-1}-4 E-2 k+2 E \sqrt{2 k+2 E-1}+1)}{\sqrt{2 k+2 E-1}}>0 .
$$

This is positive if the numerator is positive, or if

$$
(1+2 E) \sqrt{2 k+2 E-1}>4 E+2 k-1 .
$$

After taking squares, factoring and smaller manipulations, we find that this must be true since

$$
\left(4 E^{2}-2 E-2 k+1\right)=2 E(2 E-1)+1-2 k<0,
$$

which shows that $\bar{n}^{A}$ is indeed monotonic in $k$.

Finally, taking derivatives of $\bar{n}^{A}$ with respect to $E$ :

$$
\frac{\partial \bar{n}^{A}}{\partial E}=\frac{\partial}{\partial E}\left(\frac{(2 E+2 k-1)^{\frac{1}{2}}-E+k-1}{(2 k-1)}\right)=\frac{1}{2 k-1}\left(\frac{1}{\sqrt{2 k+2 E-1}}-1\right)>0 .
$$

Consider finally the case of $\bar{n}^{A}<\frac{1}{2}$.

We show the monotonicity of $\bar{n}^{A}$ as defined in (A.21), with respect to $E$ and $n$. With respect to $E$, the monotonicity follows immediately from (A.21), as neither $x$ nor $R$ depend on $E$. With respect to $k$ the argument is more involved as both $x$ and $R$ depend on $k$. Moreover, $R$ depends on $n$.

Taking this endogeneity into account, the derivative of (A.21) gives:

$$
\frac{\partial \bar{n}^{A}}{\partial k}=\frac{-R x^{\prime}+x R^{\prime}}{(x-R)^{2}} E .
$$


Since we want to show that $\frac{\partial \bar{n}^{A}}{\partial k}>0$, we need to show that:

$$
-R x^{\prime}+x R^{\prime}>0 \Leftrightarrow R^{\prime}>\frac{R}{x} x^{\prime} .
$$

Further, note for the total differential $R^{\prime}$ that:

$$
R^{\prime}=\frac{d R}{d k}=\frac{\partial R}{\partial k}+\frac{\partial R}{\partial n} \frac{\partial n}{\partial k}>\frac{\partial R}{\partial k}
$$

since

$$
\frac{\partial R}{\partial n^{A}}=\frac{\partial}{\partial n^{A}}\left(\frac{1-n^{A}}{\frac{1}{4}+k\left(\frac{1}{2}-n^{A}\right)}\right)=4\left(4 k n^{A}-2 k-1\right)^{-2}(2 k-1)>0
$$

and since by assumption, $\frac{\partial \bar{n}^{A}}{\partial k}>0$. So a sufficient condition is:

$$
\frac{\partial R}{\partial k}>x^{\prime} \frac{R}{x}
$$

(we show in effect that keeping $\bar{n}^{A}$ constant in the differential $\frac{\partial R}{\partial k}$, it must be that $\frac{\partial \bar{n}^{A}}{\partial k}>0$. Taking this effect on $\frac{d R}{d k}$ into account, the effect must hold a fortiori).

Then:

$$
x^{\prime}=\frac{d x}{d k}=-\frac{1}{(2 k-1) \sqrt{2 k-1}} .
$$

Both derivatives are negative. Using these expressions, substituting for $R / x$ and simplifying, (A.26) can be rewritten as

$$
\frac{8\left(1-n^{A}\right)\left(1-2 n^{A}\right)}{\left(4 k n^{A}-2 k-1\right)^{2}}<\frac{1}{2 k-1} \frac{1-n^{A}}{\frac{1}{4}+k\left(\frac{1}{2}-n^{A}\right)} .
$$

Taking derivative w.r.t. $n^{A}$ on the lhs of (A.27):

$$
\frac{\partial}{\partial n^{A}}\left(\frac{8\left(1-n^{A}\right)\left(1-2 n^{A}\right)}{\left(4 k n^{A}-2 k-1\right)^{2}}\right)=\frac{8\left(-4 n^{A}(1-k)-2 k+3\right)}{\left(4 k n^{A}-2 k-1\right)^{3}}<0,
$$

and on the rhs of (A.27):

$$
\frac{\partial}{\partial n^{A}}\left(\frac{1-n^{A}}{\frac{1}{4}+k\left(\frac{1}{2}-n^{A}\right)}\right)=\frac{4(2 k-1)}{\left(4 k n^{A}-2 k-1\right)^{2}}>0 .
$$

So a sufficient condition is that (A.27) holds at $n^{A}=0$ :

$$
\frac{8}{(-2 k-1)^{2}}<\frac{1}{2 k-1} \frac{1}{\frac{1}{4}+k \frac{1}{2}}
$$


which is equivalent to:

$$
\frac{8}{(1+2 k)}<\frac{4}{2 k-1}
$$

and this condition is true for all $k \in\left(\frac{1}{2}, 1\right)$.

\section{Proof of Proposition 3.}

Part (i). We already know that $n^{A}=E+k$ is optimal in the class of cherry-picking allocations, and this allocation is feasible in Region 1 by definition. Finally, the proof of part (ii) below implies that $n^{A}=E+k$ is superior to any risk-shifting allocation.

Part (ii). Here, we consider situations where the optimal $n^{A}=E+k$ without risk-shifting is not feasible as $\bar{n}^{A}<E+k$. The boundaries for $\bar{n}^{A}$ are known from section 4.2. We prove that $n^{A}=\bar{n}^{A}>\frac{1}{2}$ is optimal. Consider first the case $n^{A}>\bar{n}^{A}$, meaning that Bank $A$ is risk-shifting. Then, Bank $B$ faces no bankruptcy risk, and Bank $A$ earns profits of

$$
\Pi_{r}^{A}=\left(1-\tilde{t}^{A}\right)\left[\left(n^{A}-\frac{1}{2}\right) k R+\frac{1}{2} E\left[t \mid t>\tilde{t}^{A}\right] R+E-n^{A}\right] .
$$

Note that $R=\frac{1}{k}$, since we analyze bankruptcy costs in an equilibrium with risk-shifting, so that the projects expected by Bank $B$ are all safe ones. Thus, the expected bankruptcy probability, again obtained as the marginal $t$ where [.] $=0$ in Eq. (A.28), is $\tilde{t}^{A}=k(1-2 E)$. Hence,

$$
Z_{r}\left(n^{A}\right)=n^{A} z k(1-2 E),
$$

and $\frac{\partial Z_{r}}{\partial n^{A}}=z k(1-2 E)>0$. Thus, given risk-shifting, $n^{A}=\bar{n}^{A}+\varepsilon$ would be optimal.

Bankruptcy costs with cherry-picking, $Z_{c}\left(\bar{n}^{A}\right)$, are $Z_{c}\left(\bar{n}^{A}\right)=\frac{1}{2} z\left(1-\bar{n}^{A}-E\right)$, since only Bank $B$ faces positive bankruptcy risk. Hence, we have

$$
\begin{aligned}
Z_{c}\left(\bar{n}^{A}\right)-Z_{r} & =z\left(\frac{1}{2}\left(1-\bar{n}^{A}-E\right)-n^{A} k(1-2 E)\right) \\
& \leq z\left(\frac{1}{4}(1-2 E)-\frac{k(1-2 E)}{2}\right)<0,
\end{aligned}
$$

where we made use of $n^{A} \geq \frac{1}{2}, \bar{n}^{A} \geq \frac{1}{2}$ and $k \geq \frac{1}{2}$.

Part (iii). Finally, we turn to the case where $\bar{n}^{A}<\frac{1}{2}$, meaning that the bank would shift risk even if it gets only half of the projects. We show that for all $\bar{n}^{A}<\frac{1}{2}$, the optimal regulation is $n^{A} \rightarrow \bar{n}^{A}$, which could either be the $\bar{n}^{A}$ which is the maximum value for cherry-picking, or the limit for the minimal value where risk-shifting occurs $\left(n^{A} \searrow \bar{n}^{A}\right)$.

To show this, we consider first the case $n^{A} \leq \bar{n}^{A}$. In this case, Bank $A$ cherry-picks, and only Bank $B$ is risky. Bank $B$ 's bankruptcy probability is given by

$$
\left(\frac{1}{2}-n^{A}\right) k R+\frac{1}{2} \tilde{t}^{B} R+E-\left(1-n^{A}\right)=0
$$


which yields

$$
\tilde{t}^{B}=2 \frac{1-n^{A}-E-\left(\frac{1}{2}-n^{A}\right) k R}{R} .
$$

Substituting the interest factor which is given by $R=\frac{1-n^{A}}{\frac{1}{4}+k\left(\frac{1}{2}-n^{A}\right)}$ and simplifying gives

$$
\tilde{t}^{B}=\frac{1}{2}-\frac{E\left(\frac{1}{2}+k\left(1-2 n^{A}\right)\right)}{1-n^{A}} .
$$

The associated welfare loss is

$$
\begin{aligned}
Z_{c} & =Z_{c}^{B}=\left(1-n^{A}\right) \tilde{t}^{B} \\
& =\left(1-n^{A}\right) \frac{1}{2} z-E\left(\frac{1}{2}+k\left(1-2 n^{A}\right)\right) z .
\end{aligned}
$$

We find that

$$
\frac{\partial Z_{c}}{\partial n^{A}}=2 k E z-\frac{1}{2} z<0
$$

where the inequality follows from $E \leq \frac{1}{2(1+2 k)}$. Hence, the regulator will choose the largest possible $n^{A}$ in this case, $n^{A}=\bar{n}^{A}$.

Consider then the case of $n^{A}>\bar{n}^{A}$. In this case, Bank $A$ chooses risk-shifting, and either both banks or only Bank $A$ are risky.

Bank $A$ will be bankrupt if

$$
n^{A} \tilde{t}^{A} R+E-n^{A}=0 .
$$

Hence

$$
\tilde{t}^{A}=\frac{n^{A}-E}{n^{A} R}=\frac{1}{2} \frac{\left(n^{A}-E\right)\left(k-n^{A}+\frac{1}{2}\right)}{n^{A}\left(1-n^{A}\right)},
$$

where the last equality obtains after substituting the interest factor $R=2 \frac{1-n^{A}}{k-n^{A}+\frac{1}{2}}$ (with Bank $B$ financing $1-n^{A}$ projects of which $\frac{1}{2}$ are safe).

Consider first the subcase where $n^{A}$ is small enough so that both banks bear bankruptcy risk. The bankruptcy risk of Bank $B, \tilde{t}^{B}$, is given by:

$$
\tilde{t}^{B}=\frac{\left(1-n^{A}-E-\frac{1}{2} R k\right)}{R\left(\frac{1}{2}-n^{A}\right)}
$$

which we derive from:

$$
\frac{1}{2} k R+\left(\frac{1}{2}-n^{A}\right) \tilde{t}^{B} R+E-\left(1-n^{A}\right)=0 .
$$


Using $R=\frac{2\left(1-n^{A}\right)}{k-n^{A}+\frac{1}{2}}$ and simplifying, we get

$$
\tilde{t}^{B}=\frac{\left(1-n^{A}\right)\left(\frac{1}{2}-n^{A}\right)-E\left(k-n^{A}+\frac{1}{2}\right)}{2\left(1-n^{A}\right)\left(\frac{1}{2}-n^{A}\right)} .
$$

Hence, for the total bankruptcy loss, we get:

$$
\begin{aligned}
Z_{r} & =n^{A} \tilde{t}^{A}+\left(1-n^{A}\right) \tilde{t}^{B} \\
& =\frac{1}{2} \frac{\left(n^{A}-E\right)\left(k-n^{A}+\frac{1}{2}\right)}{\left(1-n^{A}\right)} z-\frac{E\left(k-n^{A}+\frac{1}{2}\right)}{1-\frac{n^{A}}{2}} z+\frac{\left(1-n^{A}\right)}{2} z .
\end{aligned}
$$

We will then show that $\frac{\partial Z_{r}}{\partial n^{A}}>0$ :

$$
\begin{aligned}
& \frac{\partial Z_{r}}{\partial n^{A}}=\left(\frac{E(3-2 k)}{\left(2-n^{A}\right)^{2}}+\frac{\left(1+2 E+2 k-4 n^{A}\right)}{4\left(1-n^{A}\right)}+\frac{\left(1+2 k-2 n^{A}\right)}{4\left(1-n^{A}\right)^{2}}\left(n^{A}-E\right)-\frac{1}{2}\right) z \\
& =\left(\frac{(2 k-1)(1-E)}{4\left(1-n^{A}\right)^{2}}+\frac{E(3-2 k)}{\left(2-n^{A}\right)^{2}}\right) z>0 .
\end{aligned}
$$

Consider then the subcase where $n^{A}$ is large enough that only Bank $A$ bears bankruptcy risk. In this case, if $n^{A}<\frac{1}{2}$, then the bankruptcy loss $Z_{r}$ is strictly increasing in $n^{A}$. If $n^{A} \geq \frac{1}{2}$, then Bank $A$ 's bankruptcy probability is given by expression (A.28), and the total loss $Z_{r}$ given by expression (A.29) is again strictly increasing in $n^{A}$.

Taking both subcases of the case $n^{A}>\bar{n}^{A}$ together, we have shown that the regulator wants to choose the $n^{A}$ as small as possible, hence $n^{A}=\bar{n}^{A}$, completing the proof that the regulator will always implement $\bar{n}^{A}$ if $\bar{n}^{A}<\frac{1}{2}$.

Finally, we compare the welfare losses under risk-shifting $\left(n^{A}=\bar{n}^{A}+\varepsilon, \varepsilon \rightarrow 0\right)$ and under cherry-picking $\left(n^{A}=\bar{n}^{A}\right)$ in this region that are given in Eq. (A.31) and (A.32). Consider the difference

$$
Z_{c}-Z_{r}=\left(-E\left(\frac{1}{2}+k\left(1-2 n^{A}\right)\right)\right) z-\left(\frac{1}{2} \frac{\left(n^{A}-E\right)\left(k-n^{A}+\frac{1}{2}\right)}{\left(1-n^{A}\right)}-\frac{E\left(k-n^{A}+\frac{1}{2}\right)}{1-\frac{n^{A}}{2}}\right) z .
$$

First, consider the upper end of the interval, where $k$ and $E$ are such that $\bar{n}^{A} \rightarrow \frac{1}{2}$. Then, after substituting $n^{A}=\frac{1}{2}$ and simplifying, Eq. (A.34) yields:

$$
Z_{c}-Z_{r}=\frac{7}{4} k z E-\frac{1}{2} z E-\frac{1}{2} k z<0,
$$


which is negative since $E<\frac{1}{4}$. Finally, we consider the smallest possible value of $\bar{n}^{A}$ with cherry-picking, i.e. $\left.k \rightarrow \frac{1}{2}\right)$. Then

$$
\begin{aligned}
\lim _{k \rightarrow \frac{1}{2}}\left(Z_{c}-Z_{r}\right) & =\left(\frac{1}{2}(1-E)-E\left(\frac{1}{2}+\frac{1}{2}(1-2 E)\right)-\left(\frac{(1-E)}{2}-\frac{E\left(\frac{1}{2}-E+\frac{1}{2}\right)}{1-\frac{E}{2}}\right)\right) z \\
& =\left(-E(1-E)+\frac{E(1-E)}{1-\frac{E}{2}}\right) z>0 .
\end{aligned}
$$

Hence, for $k \rightarrow \frac{1}{2}$, which implies $\bar{n}^{A} \rightarrow E$, risk-shifting is always preferred.

\section{Proof of Lemma 3.}

$Z_{i} \leq Z_{h}$ is implied by the proof that $n^{A}=\bar{n}^{A}$ is optimal in Region 3 of Proposition 3. $Z_{i}<Z_{u}$ in Region 1 can be shown as follows: Under Basel II, the regulator implements $n^{A}=E+k$. Then, total bankruptcy costs are given by $Z_{i}(E+k)=\frac{1-k-2 E}{2} z$. On the other hand, without investment in an IRS (Basel I regulation), total bankruptcy costs are $Z_{u}=z\left(\frac{1}{2}-E(1+2 k)\right)$. Thus, we have

$$
Z_{u}-Z_{c}(E+k)=2 k z\left(\frac{1}{4}-E\right)>0 .
$$

To see that $Z_{i} \lessgtr Z_{u}$ in Regions 2 and 3 , we have to distinguish between the cases where $\frac{1}{2} \leq$ $\bar{n}^{A}<E+k$ and where $\bar{n}^{A}<\frac{1}{2}$. We start with the first case where we know that the regulator implements $\bar{n}^{A}$ which ensures cherry-picking. We already know from Proposition 3 that total bankruptcy costs are then $Z_{i}\left(\bar{n}^{A}\right)=\frac{1}{2} z\left(1-\bar{n}^{A}-E\right)$, so that the we have

$$
Z_{u}-Z_{i}\left(\bar{n}^{A}\right)=z\left(\frac{1}{2} \bar{n}^{A}-2 k E-\frac{1}{2} E\right) .
$$

Now using the closed-form expression for $\bar{n}^{A}$ from Eq. (A.22), we get

$$
Z_{u}-Z_{i}\left(\bar{n}^{A}\right)=\frac{z}{2}\left[\frac{(2 E+2 k-1)^{\frac{1}{2}}-E+k-1}{(2 k-1)}-E-4 k E\right] .
$$

We have then to show that both $Z_{u}>Z_{i}\left(\bar{n}^{A}\right)$ and $Z_{u}<Z_{i}\left(\bar{n}^{A}\right)$ can occur in this case. Considering the minimum $k=\frac{1}{2}$, we get

$$
Z_{u}-Z_{i}\left(\bar{n}^{A}\right)=-\frac{z}{2}\left(\frac{\frac{1}{2}+E-\sqrt{2 E}}{(2 k-1)}+E+2 E\right)<0,
$$

which shows that the uniform sector can be superior even if investment costs are neglected. For the maximum $k=1-E$, we get 


$$
Z_{u}-Z_{i}\left(\bar{n}^{A}\right)=\frac{z}{2}\left(\frac{(2(1-k)+2 k-1)^{\frac{1}{2}}-2(1-k)}{(2 k-1)}-(1+4 k)(1-k)\right)=\frac{z k}{2}(4 k-3)
$$

which is positive for any $k \geq \frac{3}{4}$, so that indeed both situations might occur for $C=0$. We can also show (but omit it here) that $Z_{u}-Z_{i}\left(\bar{n}^{A}\right)$ is concave in $k$, so that there will be exactly one point where $Z_{u}-Z_{i}\left(\bar{n}^{A}\right)=0$. In exactly the same manner (also omitted) it can be proven that $Z_{i} \lessgtr Z_{u}$ if $\bar{n}^{A}<\frac{1}{2}$.

Proof of Proposition 4. Recall that all subsidies/taxes are assumed to be neutral from a welfare point of view. Therefore, we can continue to compare only bankruptcy losses $Z$ and investment costs $C$ as the only terms in the overall welfare that change between any two scenarios.

Part (i). If the preferences are aligned, Bank $A$ invests if and only if this is optimal, so that no subsidies are required. Underinvestment: As $C \leq Z_{u}-Z_{i}$, the regulator prefers Basel II. And since Bank $A$ invests if and only if $\Pi_{i}-\Pi_{u}+s \geq C$, a minimum subsidy of $s=C-\left(\Pi_{i}-\Pi_{u}\right)$ is required. Overinvestment: In this case, the regulator prefers Basel I. Suppose that the regulator chooses $s<0$ such that $C+s>\Pi_{i}-\Pi_{u}$. Then, Bank $A$ will not apply for a license. If $C>\Pi_{h}-\Pi_{u}$, the best Bank $A$ can do is then not to invest, such that the regulator reaches the desired outcome Basel I. If $C \leq \Pi_{h}-\Pi_{u}$, however, Bank $A$ prefers an investment with hiding (which implies an allocation of $\frac{1}{2}$ and risk-shifting) to not investing. Since this cannot be avoided by taxes, and because $Z_{i}<Z_{h}$, the best reachable outcome is then to accommodate Basel II.

Part (ii). If the preferences are aligned or there is overinvestment and if $Z_{u}-Z_{i} \geq C$, the regulator prefers that the bank be certified as an IRB-bank since $Z_{i}<Z_{h}$. Bank $A$ will always prefer to invest and hide since $\bar{n}^{A}<\frac{1}{2}$ which implies $\Pi_{h}>\Pi_{i}$. Hence the regulator will offer sufficient subsidies $s$, as stated in the Proposition. If $Z_{u}-Z_{i}<C$, then preferences will be aligned, and the bank will take the optimal decision of not investing without the regulator's intervention. If there is an underinvestment problem, then the same situation arises as in part (i): As $C \leq Z_{u}-Z_{i}$ in this case, the regulator prefers Basel II. Bank $A$ invests only if a subsidy of $s \geq C-\left(\Pi_{i}-\Pi_{u}\right)$ is pledged, and the regulator will offer this subsidy since there is no other cost involved. 


\section{CFS Working Paper Series:}

\begin{tabular}{|c|c|c|}
\hline No. & Author(s) & Title \\
\hline $2004 / 16$ & $\begin{array}{l}\text { Torben G. Andersen } \\
\text { Tim Bollerslev } \\
\text { Francis X. Diebold } \\
\text { Jin Wu }\end{array}$ & Realized Beta: Persistence and Predictability \\
\hline $2004 / 17$ & $\begin{array}{l}\text { Uwe Walz } \\
\text { Douglas Cumming }\end{array}$ & $\begin{array}{l}\text { Legality and Venture Governance around the } \\
\text { World }\end{array}$ \\
\hline $2004 / 18$ & $\begin{array}{l}\text { Elena Carletti } \\
\text { Vittoria Cerasi } \\
\text { Sonja Daltung }\end{array}$ & $\begin{array}{l}\text { Multiple-bank lending: diversification and } \\
\text { free-riding in monitoring }\end{array}$ \\
\hline $2004 / 19$ & $\begin{array}{l}\text { Torben G. Andersen } \\
\text { Tim Bollerslev } \\
\text { Francis X. Diebold } \\
\text { Clara Vega }\end{array}$ & $\begin{array}{l}\text { Real-Time Price Discovery in Stock, Bond and } \\
\text { Foreign Exchange Markets }\end{array}$ \\
\hline $2004 / 20$ & $\begin{array}{l}\text { Lars Norden } \\
\text { Martin Weber }\end{array}$ & $\begin{array}{l}\text { The comovement of credit default swap, bond and } \\
\text { stock markets: an empirical analysis }\end{array}$ \\
\hline $2004 / 21$ & Andreas Jobst & $\begin{array}{l}\text { The Basle Securitisation Framework Explained: } \\
\text { The Regulatory Treatment of Asset Securitisation }\end{array}$ \\
\hline $2004 / 22$ & $\begin{array}{l}\text { Robert G. King } \\
\text { Alexander L. Wolman }\end{array}$ & $\begin{array}{l}\text { Monetary Discretion, Pricing Complementarity } \\
\text { and Dynamic Multiple Equilibria }\end{array}$ \\
\hline $2004 / 23$ & $\begin{array}{l}\text { Jordi Galí } \\
\text { J.David López-Salidoz } \\
\text { Javier Vallés }\end{array}$ & $\begin{array}{l}\text { Understanding the Effects of Government } \\
\text { Spending on Consumption }\end{array}$ \\
\hline $2004 / 24$ & $\begin{array}{l}\text { Athanasios Orphanides } \\
\text { John C. Williams }\end{array}$ & $\begin{array}{l}\text { The Decline of Activist Stabilization Policy: } \\
\text { Natural Rate Misperceptions, Learning, and } \\
\text { Expectations }\end{array}$ \\
\hline $2004 / 25$ & $\begin{array}{l}\text { Eberhard Feess } \\
\text { Ulrich Hege }\end{array}$ & $\begin{array}{l}\text { The Basel II Accord: Internal Ratings } \\
\text { and Bank Differentiation }\end{array}$ \\
\hline
\end{tabular}

Copies of working papers can be downloaded at http://www.ifk-cfs.de 